\title{
Aggregation and Phase Equilibria of Fluorinated
}

\section{Ionic Liquids}

Nicole S. M. Vieira ${ }^{\text {a,b }}$, Joana C. Bastos ${ }^{\text {a }, \text { Carolina Hermida-Merino }}{ }^{\text {a,c }}$, María J. Pastoriza-

Gallego $^{\mathrm{c}}$, Luís P. N. Rebelo ${ }^{\mathrm{a}}$, Manuel M. Piñeiro ${ }^{\mathrm{c}}$, João M. M. Araújo a ${ }^{\text {and Ana B. Pereiro }}{ }^{\text {a, * }}$

a LAQV, REQUIMTE, Departamento de Química, Faculdade de Ciências e Tecnologia, Universidade Nova de Lisboa (FCT NOVA), 2829-516 Caparica, Portugal. (ns.vieira@campus.fct.unl.pt N.S.M.V.; jc.bastos@campus.fct.unl.pt J.C.B.; luis.rebelo@fct.unl.pt L.P.N.R.; jmmda@fct.unl.pt J.M.M.A)

${ }^{\mathrm{b}}$ Instituto de Tecnologia Química e Biológica António Xavier, Universidade Nova de Lisboa (ITQB NOVA), Avenida da República, 2780-157 Oeiras, Portugal

c Departamento de Física Aplicada, Facultade de Ciencias, Universidade de Vigo, E36310 Vigo, Spain (cahermida@uvigo.es C.H.-M.; mjpg@uvigo.es M.J.P.-G.; mmpineiro@uvigo.es. M.M.P.)

* Correspondence to: A.B.Pereiro, E-mail: anab@fct.unl.pt; Fax: (+351) 212948550; Tel: (+351) 212948300 


\begin{abstract}
In this work a specific family of ionic liquids, denominated fluorinated ionic liquids, with fluorine tags equal or longer than four carbon atoms, are fully characterized in order to understand their solubility and self-aggregation in aqueous solutions. The numerous combinations between cations and anions make these compounds a feasible option for the replacement of traditional and toxic surfactants used in the industrial and biomedical field. In this work, the increment of both hydrogenated and fluorinated side chain lengths, the influence of the cation headgroup (imidazolium and cholinium) as well as the difference between perfluorobutanesulfonate and perfluoropentanoate anions were studied. The liquid-liquid phase equilibria of fluorinated ionic liquids based on the perfluorobutanesulfonate anion with water was carried out. The self-aggregation behaviour of the different fluorinated ionic liquids in aqueous solutions was also determined using conductimetric titration, surface tension measurements and transmission electron microscopy. Several thermodynamic and surface parameters were obtained and used to discuss the aggregation process. These novel characterized fluorinated ionic liquids demonstrate an improved surface activity and aggregation behaviour, driven essentially by the increment of both hydrogenated and fluorinated chain lengths.
\end{abstract}

Keywords: Fluorinated ionic liquids; Liquid-liquid phase equilibria; Solubility; Self-aggregation; Surface activity. 


\section{Introduction}

Perfluorinated compounds (PFCs) are anthropogenic substances with exceptional physicochemical properties which made them widely used in a variety of industrial and commercial products $[1,2]$. In the past decades, environmental exposures of some of these substances have been identified in humans, as well as in certain wildlife samples [3-7]. Consequently, some surfactants based on PFCs were considered persistent organic pollutants because they can be toxic, extremely resistant to degradation, bioaccumulate in food chains, and can have long half-lives $[8,9]$. Taking into account the benefits of these compounds in different applications, the search for greener and sustainable compounds has become a challenging process.

Fluorinated ionic liquids (FILs) are ionic liquids that contain a fluorinated alkyl chain with at least four carbon atoms [10]. FILs display unique properties such as low surface tension, high capacity for dissolving gases, improved surfactant behaviour, low intensity interactions with most organic compounds, great solvation capacity, and high chemical and biological inertness [11,12]. The enormous number of combinations between cations and anions allow to manipulate the behaviour of these compounds enhancing their properties for a defined purpose [13]. These innovative fluoroalkyl chemicals can substitute PFCs in different industrial processes for example, as surfactants [14], lubricants [15], and in the production of insecticides [16]. These applications can be feasible because FILs based on perfluorobutanesulfonate and perfluoropentanoate anions have demonstrated negligible cytotoxicity in different human cell lines, and low acute ecotoxicity in several aquatic organisms $[10,17,18]$.

On the other hand, the high solubility and low energy interactions presented in these FILs can be explained by the very strong C-F bonds present in their structure [12,19]. Additionally, these compounds can form three nanosegregated domains: one polar and two nonpolar (one aliphatic and other perfluorinated) [12]. Their self-aggregation and the formation of these different nanosegregated domains influence their surface properties exhibiting unexpected behaviours on the surface tension 
[20]. One of the goals of this work is to understand the impact of the hydrogenated and fluorinated clusters/domains on the formation, and stability of self-aggregated structures in aqueous solutions. The increment of the alkyl side chain of 1-alkyl-3-methylimidazolium perfluorobutanesulfonate $\left[\mathrm{C}_{n} \mathrm{C}_{1} \mathrm{Im}\right]\left[\mathrm{C}_{4} \mathrm{~F}_{9} \mathrm{SO}_{3}\right]$ family, as well as the increment of the fluorinated chain length, from perfluorobutanesulfonate $\left(\left[\mathrm{C}_{4} \mathrm{~F}_{9} \mathrm{SO}_{3}\right]^{-}\right)$to perfluorooctanesulfonate $\left(\left[\mathrm{C}_{8} \mathrm{~F}_{17} \mathrm{SO}_{3}\right]^{-}\right)$in imidazolium and cholinium-based FILs, were herein studied. Furthermore, the influence of the cation headgroup (imidazolium and cholinium), as well as the anion core (perfluorobutanesulfonate and perfluoropentanoate) were also analysed for the aforementioned parameters.

With this goal in mind, the phase equilibria and ionic conductivity were determined for the FILs 1-butyl-3-methylimidazolium perfluorobutanesulfonate, $\left[\mathrm{C}_{4} \mathrm{C}_{1} \operatorname{Im}\right]\left[\mathrm{C}_{4} \mathrm{~F}_{9} \mathrm{SO}_{3}\right]$, and 1-decyl-3methylimidazolium perfluorobutanesulfonate, $\left[\mathrm{C}_{10} \mathrm{C}_{1} \mathrm{Im}\right]\left[\mathrm{C}_{4} \mathrm{~F}_{9} \mathrm{SO}_{3}\right]$ in aqueous solutions. These studies were compared with the results obtained in previous works [21,22] in order to obtain general trends. Some relevant parameters such as thermodynamic properties related to the dissolution of water in FILs, critical aggregation concentrations, degree of ionization of the aggregates and counterion binding, were also determined for these FILs and for the ethyl-3-methylimidazolium perfluoropentanoate, $\left[\mathrm{C}_{2} \mathrm{C}_{1} \mathrm{Im}\right]\left[\mathrm{C}_{4} \mathrm{~F}_{9} \mathrm{CO}_{2}\right]$, cholinium perfluoropentanoate $\left[\mathrm{N}_{1112(}(\mathrm{OH})\right]\left[\mathrm{C}_{4} \mathrm{~F}_{9} \mathrm{CO}_{2}\right]$ and for the cholinium perfluorooctanesulfonate $\left[\mathrm{N}_{1112(\mathrm{OH})}\right]\left[\mathrm{C}_{8} \mathrm{~F}_{17} \mathrm{SO}_{3}\right]$. Finally, measurements of the surface tension and transmission electron microscopy (TEM) have also been performed for $\left[\mathrm{C}_{n} \mathrm{C}_{1} \mathrm{Im}\right]\left[\mathrm{C}_{\mathrm{x}} \mathrm{F}_{2 \mathrm{x}+1} \mathrm{SO}_{3}\right](\mathrm{n}=2,4,6,8,10$ and 12 and $\mathrm{x}=4$ and 8$)$ family and for $\left[\mathrm{N}_{1112(\mathrm{OH})}\right]\left[\mathrm{C}_{4} \mathrm{~F}_{9} \mathrm{SO}_{3}\right]$, $\left[\mathrm{N}_{1112(\mathrm{OH})}\right]\left[\mathrm{C}_{4} \mathrm{~F}_{9} \mathrm{CO}_{2}\right]$ and $\left[\mathrm{N}_{1112(\mathrm{OH})}\right]\left[\mathrm{C}_{8} \mathrm{~F}_{17} \mathrm{SO}_{3}\right]$. The last experiments complement the results of the aggregation behaviour and enable the calculation of the micellar size, maximum surface excess concentration, effectiveness of the surface tension reduction, minimum area occupied per molecule and critical packing parameters. 


\section{Experimental Section}

\subsection{Materials}

1-Ethyl-3-methylimidazolium perfluorobutanesulfonate $\left(\left[\mathrm{C}_{2} \mathrm{C}_{1} \mathrm{Im}\right]\left[\mathrm{C}_{4} \mathrm{~F}_{9} \mathrm{SO}_{3}\right], \geq 97 \%\right.$ mass fraction purity), 1-hexyl-3-methylimidazolium perfluorobutanesulfonate $\left(\left[\mathrm{C}_{6} \mathrm{C}_{1} \mathrm{Im}\right]\left[\mathrm{C}_{4} \mathrm{~F}_{9} \mathrm{SO}_{3}\right],>99 \%\right.$ mass fraction purity), 1-mehtyl-3-octylimidazolium perfluorobutanesulfonate $\left(\left[\mathrm{C}_{8} \mathrm{C}_{1} \mathrm{Im}\right]\left[\mathrm{C}_{4} \mathrm{~F}_{9} \mathrm{SO}_{3}\right]\right.$, $>99 \%$ mass fraction purity), 1-dodecyl-3-methylimidazolium perfluorobutanesulfonate $\left(\left[\mathrm{C}_{12} \mathrm{C}_{1} \mathrm{Im}\right]\left[\mathrm{C}_{4} \mathrm{~F}_{9} \mathrm{SO}_{3}\right], \quad>98 \%\right.$ mass fraction purity), 1-ethyl-3-methylimidazolium perfluoroctanesulfonate $\left(\left[\mathrm{C}_{2} \mathrm{C}_{1} \operatorname{Im}\right]\left[\mathrm{C}_{8} \mathrm{~F}_{17} \mathrm{SO}_{3}\right], \geq 98 \%\right.$ mass fraction purity) and cholinium perfluorobutanesulfonate, $\left(\left[\mathrm{N}_{1112(\mathrm{OH})}\right]\left[\mathrm{C}_{4} \mathrm{~F}_{9} \mathrm{SO}_{3}\right],>97 \%\right.$ mass fraction purity) were supplied by IoLiTec GmbH. 1-Butyl-3-methylimidazolium perfluorobutanesulfonate ([ $\left.\mathrm{C}_{4} \mathrm{C}_{1} \mathrm{Im}\right]\left[\mathrm{C}_{4} \mathrm{~F}_{9} \mathrm{SO}_{3}\right], 98 \%$ mass fraction purity), 1-decyl-3-methylimidazolium perfluorobutanesulfonate $\left(\left[\mathrm{C}_{10} \mathrm{C}_{1} \mathrm{Im}\right]\left[\mathrm{C}_{4} \mathrm{~F}_{9} \mathrm{SO}_{3}\right]\right.$, 98\% mass fraction purity), 1-ethyl-3-methylimidazolium perfluoropentanoate, $\left(\left[\mathrm{C}_{2} \mathrm{C}_{1} \mathrm{Im}\right]\left[\mathrm{C}_{4} \mathrm{~F}_{9} \mathrm{CO}_{2}\right]\right.$, 99\% mass fraction purity) and cholinium perfluoropentanoate $\left(\left[\mathrm{N}_{1112(\mathrm{OH})}\right]\left[\mathrm{C}_{4} \mathrm{~F}_{9} \mathrm{CO}_{2}\right], 98 \%\right.$ mass fraction purity), were previously synthetized in our lab through the ion exchange resin method $[17,23,24]$.

In this work, cholinium perfluorooctanesulfonate, $\left[\mathrm{N}_{1112(\mathrm{OH})}\right]\left[\mathrm{C}_{8} \mathrm{~F}_{17} \mathrm{SO}_{3}\right]$, was synthetized according to the same ion exchange resin method (synthesis procedure in Supporting Information (SI)). All FILs were dried under a 4 Pa vacuum with a continuous stirring at $323.15 \mathrm{~K}$ for at least 48 h before their use. Karl Fisher (KF) titration technique (Methonm Ion analysis, 831 KF Coulometer) was used to calculate the water content in FILs and experimental results show values less than 100 ppm. In order to confirm the purity of these compounds, ${ }^{1} \mathrm{H}$ and ${ }^{19} \mathrm{~F}$ NMR were performed. The chemical structures of the ionic liquids used in this work are presented in Table 1. 
Table 1

Chemical structures and acronyms of the FILs used in this work.

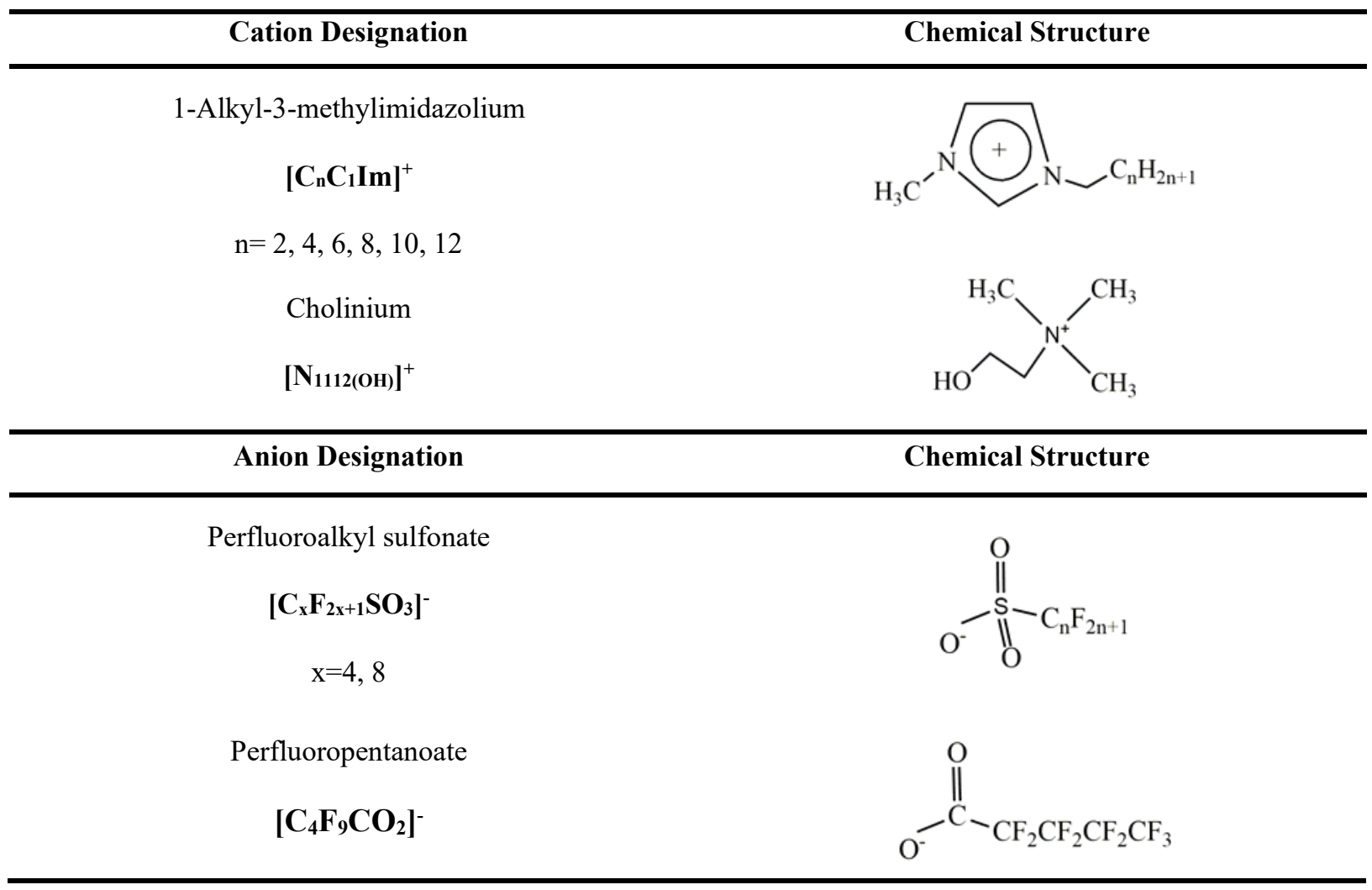

\subsection{Liquid-liquid Equilibria (LLE)}

In order to determine the temperature-composition phase diagrams, the turbidity of the binary system FIL + water was analysed using a visual method at atmospheric pressure. Initial immiscible samples were prepared directly in a Pyrex glass cells with incorporated magnetic stirrers using an analytical high-precision balance (uncertainty of $\pm 0.00002 \mathrm{~g}$ ). Then, the cell was immersed in a thermostatic bath (a mixture of water and ethylene glycol was used as thermostatic fluid) and both mixture and thermostatic fluid were continuously stirred. The liquid-liquid phase transition was accomplished by taking the temperature when turbidity of the system disappeared. The temperature was measured using a four-wire platinum resistance Pt100 thermometer coupled with a Keithley 199 multimeter (uncertainty of $0.01 \mathrm{~K}$ ). The uncertainty of the overall temperature transitions using this visual method is estimated to be $\pm 0.5 \mathrm{~K}$ and the uncertainty of the mass fraction is \pm 0.0001 . 


\subsection{Ionic Conductivity Measurements}

The ionic conductivities were performed with a CDM210 Radiometer Analytical conductimeter using a CDC749 electrode in a glass cell with a magnetic stirrer at $298.15 \mathrm{~K}$. The equipment was calibrated for each temperature by using a certified $0.01 \mathrm{D} \mathrm{KCl}$ standard solution provided by Radiometer Analytical. The cell was thermostatized with a water bath and the temperature was measured using a platinum resistance thermometer coupled to a Keithley 199 multimeter (uncertainty of $\pm 0.01 \mathrm{~K}$ ). Each aqueous solution was added to the cell and stirred for the experimental measurements. Conductivity was measured at least three times and the uncertainty of the measurements is estimated to be $1 \%$.

\subsection{Surface Tension Measurements}

The surface tension was measured with a Lauda TVT2 tensiometer at $298.15 \mathrm{~K}$ using the hanging drop tensiometer method. The equipment was thermostatized using a Polyscience temperature controller where the temperature was regulated with a D20KP Lauda thermometer (uncertainty of \pm $0.01 \mathrm{~K})$. The equipment is composed of a control and a mechanical unit which were connected to a PC-controlled instrument that provides a precise measurement. The calibration of the needles supplied by the company was confirmed with compounds with known surface tensions. Experimental values were measured at least three times and the reported data are the average value with an uncertainty of $\pm 0.07 \mathrm{mN} / \mathrm{m}$.

\subsection{Transmission Electron Microscopy (TEM)}

The samples analysed with microscopy were placed on a 400 mesh copper grid with $3 \mathrm{~mm}$ diameter using a formvar film. A filter paper was used to remove the excess of aqueous solution. Solutions were dried and measured using a JEOL JEM1010 microscope at an acceleration voltage of $100 \mathrm{kV}$ equipped with a tungsten filament as electron source. 


\section{Results and discussion}

\subsection{Liquid-liquid Equilibria (LLE) and Thermodynamic Analysis}

In order to evaluate the feasibility of replacing PFCs with FILs in industrial applications, the phase equilibria of FILs based on the perfluorobutanesulfonate anion $\left(\left[\mathrm{C}_{n} \mathrm{C}_{1} \operatorname{Im}\right]\left[\mathrm{C}_{4} \mathrm{~F}_{9} \mathrm{SO}_{3}\right]\right.$ family, with $n$ from 2 to 12) with water was analysed in a temperature range from $T=298.15$ to $353.15 \mathrm{~K}$ at atmospheric pressure. The phase transitions of the FILs with the shortest hydrogenated alkyl chain $\left(\left[\mathrm{C}_{2} \mathrm{C}_{1} \mathrm{Im}\right]\left[\mathrm{C}_{4} \mathrm{~F}_{9} \mathrm{SO}_{3}\right]\right)$ were not determined due to its complete water miscibility. The rich selfassembled behaviour of $\left[\mathrm{C}_{2} \mathrm{C}_{1} \mathrm{Im}\right]\left[\mathrm{C}_{4} \mathrm{~F}_{9} \mathrm{SO}_{3}\right]$ in the aqueous medium justifies this total water solubility [22].

The $\left[\mathrm{C}_{4} \mathrm{~F}_{9} \mathrm{SO}_{3}\right]^{-}$anion is common to all FILs of the $\left[\mathrm{C}_{n} \mathrm{C}_{1} \mathrm{Im}\right]\left[\mathrm{C}_{4} \mathrm{~F}_{9} \mathrm{SO}_{3}\right]$ family. Thus, only the increment of the hydrogenated alkyl chain length of the cation was considered. The following binary mixtures: $\left[\mathrm{C}_{4} \mathrm{C}_{1} \mathrm{Im}\right]\left[\mathrm{C}_{4} \mathrm{~F}_{9} \mathrm{SO}_{3}\right]+$ water and $\left[\mathrm{C}_{10} \mathrm{C}_{1} \mathrm{Im}\right]\left[\mathrm{C}_{4} \mathrm{~F}_{9} \mathrm{SO}_{3}\right]+$ water were measured in this work and were compared with those of the same family previously reported [21]. Experimental data are presented in Table S1 of SI. Fig. 1 represents the LLE behaviour for this FILs family in aqueous solutions. The influence of temperature on the LLE in the water-rich phase is small and the solubility (see Fig. 1) of the FILs in this water rich-phase is very small for all binary mixtures.

When interpreting the LLE behaviour of FILs in aqueous solutions, it is clear that the observed behaviour is related to a delicate balance between three competing effects: i) the solubility of FILs in water (hydrophobic-hydrophilic behaviour); ii) the high surfactant behaviour of these compounds; and iii) the three nanosegregated domains of these FILs [12]. Based on the experimental LLE data showed in Fig. 1, it can be observed that the solubility of water in the FIL-rich phase (Fig. 1b) increases with the increment of the hydrogenated alkyl chain length in the imidazolium cation. In this case, water may form aggregates which could grow with the increase of the hydronated alkyl side chain since the nonpolar region drives the water molecules to the polar domain of the IL [25]. Then, 
the capacity to phase separate in this case is related to the rich and high nanosegregated behaviour of these FILs.
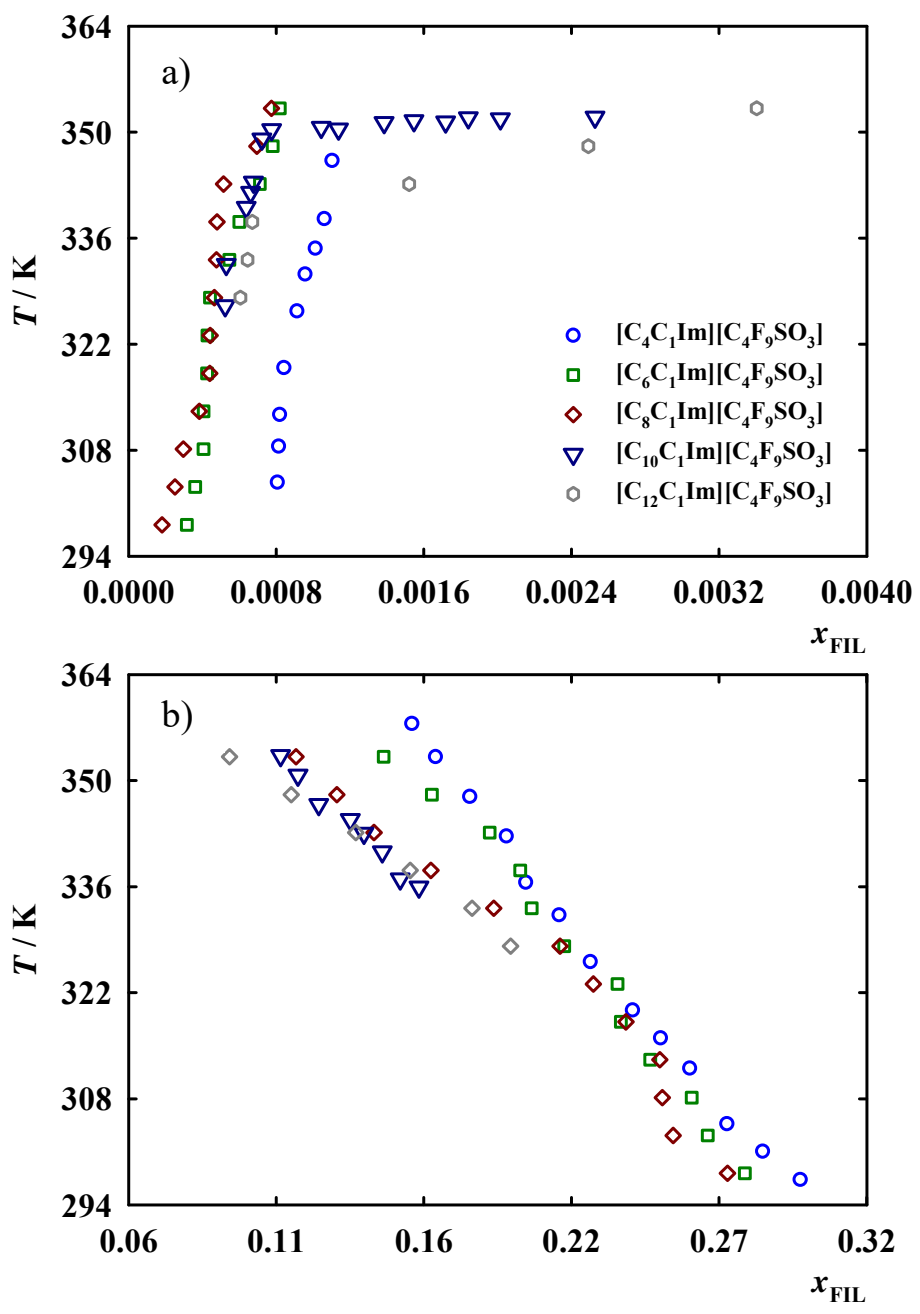

Fig. 1. Liquid-liquid phase diagrams for binary mixtures $\left[\mathrm{C}_{n} \mathrm{C}_{1} \mathrm{Im}\right]\left[\mathrm{C}_{4} \mathrm{~F}_{9} \mathrm{SO}_{3}\right]+$ water as a function of the FIL molar fraction for FILs studied in this work $\left(\left[\mathrm{C}_{4} \mathrm{C}_{1} \mathrm{Im}\right]\left[\mathrm{C}_{4} \mathrm{~F}_{9} \mathrm{SO}_{3}\right]\right.$ and $\left.\left[\mathrm{C}_{10} \mathrm{C}_{1} \mathrm{Im}\right]\left[\mathrm{C}_{4} \mathrm{~F}_{9} \mathrm{SO}_{3}\right]\right)$ and those previously reported $\left(\left[\mathrm{C}_{6} \mathrm{C}_{1} \mathrm{Im}\right]\left[\mathrm{C}_{4} \mathrm{~F}_{9} \mathrm{SO}_{3}\right],\left[\mathrm{C}_{8} \mathrm{C}_{1} \mathrm{Im}\right]\left[\mathrm{C}_{4} \mathrm{~F}_{9} \mathrm{SO}_{3}\right]\right.$ and $\left.\left[\mathrm{C}_{12} \mathrm{C}_{1} \mathrm{Im}\right]\left[\mathrm{C}_{4} \mathrm{~F}_{9} \mathrm{SO}_{3}\right]\right)$ [21] in (a) water-rich phase and (b) FIL-rich phase.

However, the opposite behaviour is observed in the water-rich phase (see Fig. 2 that represents the solubility at $T \approx 335 \mathrm{~K}$ ). The increment of the alkyl chain length (related to the increment of hydrophobic behaviour of these compounds) on the imidazolium cation decreases the solubility of FILs in aqueous solutions until an alkyl chain of hexyl / octyl. For longer alkyl chains, the high surfactant behaviour of these compounds might promote the solubility of these FILs in the water-rich phase. This behaviour has already been observed in aqueous biphasic systems with other surfactant 
ILs [26,27]. A similar trend was observed for the surface tension of the neat FILs, $\left[\mathrm{C}_{n} \mathrm{C}_{1} \mathrm{Im}\right]\left[\mathrm{C}_{4} \mathrm{~F}_{9} \mathrm{SO}_{3}\right]$ with $\mathrm{n}=2,4,6,8,10,12$ [20] where a "turn-over" on the trend was observed when $\mathrm{n}=8$ (for $\left.\left[\mathrm{C}_{8} \mathrm{C}_{1} \mathrm{Im}\right]\left[\mathrm{C}_{4} \mathrm{~F}_{9} \mathrm{SO}_{3}\right]\right)$. The reason for such behaviour was attributed to a rearrangement of the internal structure due to a competition between the nonpolar domains of FILs (hydrogenated and fluorinated) pointing toward the phase interface [20].

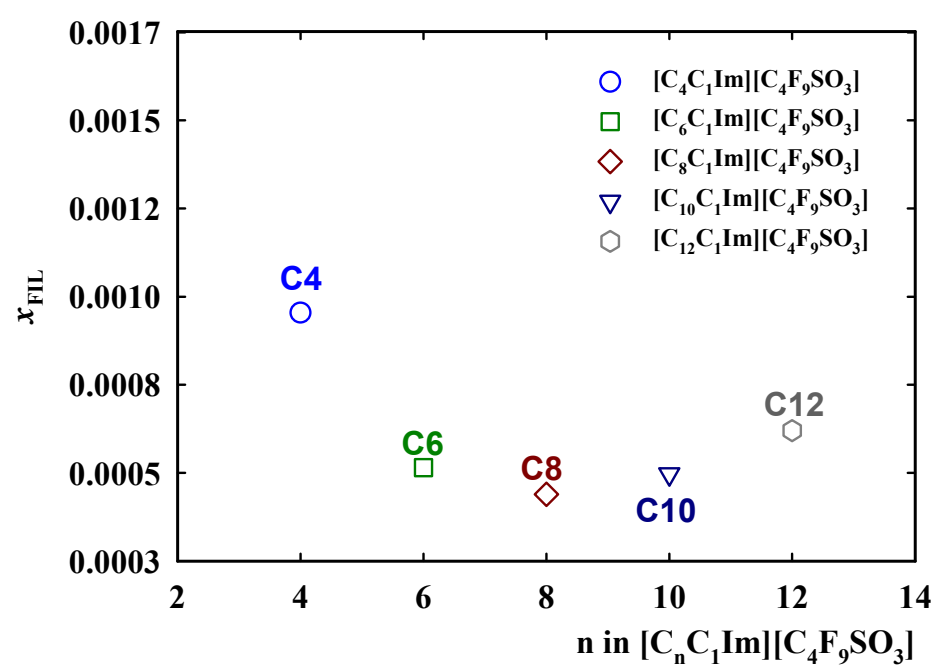

Fig. 2. Solubility of FILs in aqueous phase as a function of the imidazolium alkyl chain size at $T \approx 335 \mathrm{~K}$ for the $\left[\mathrm{C}_{\mathrm{n}} \mathrm{C}_{1} \mathrm{Im}\right]\left[\mathrm{C}_{4} \mathrm{~F}_{9} \mathrm{SO}_{3}\right]$ family.

Thermodynamic functions were calculated from the experimental LLE data in order to describe the solvation process of these systems. The thermodynamic properties of solution (standard molar Gibbs energy, $\Delta_{\text {sol }} G_{m}^{0}$, standard molar enthalpy, $\Delta_{\text {sol }} H_{m}^{0}$, and standard molar entropy, $\Delta_{\text {sol }} S_{m}^{0}$ ) control the dissolution of a liquid into another liquid. These thermodynamic properties illustrate the transference of one molecule of solute to a hypothetical dilute ideal solution where the mole fraction of the solvent is equal to one, and can be calculated as follows:

$\frac{\Delta_{\mathrm{sol}} H_{m}^{0}}{R T^{2}}=\left(\frac{\partial \ln \mathrm{x}_{\mathrm{i}}}{\partial \mathrm{T}}\right)_{p}$

$\Delta_{\mathrm{sol}} G_{m}^{0}=-R T \ln x_{i}$

$\Delta_{\mathrm{sol}} S_{m}^{0}=R\left(\frac{\partial \ln x_{i}}{\partial T} \cdot T+\ln x_{\mathrm{i}}\right)_{p}$ 
where $x_{i}, T, p$, and $R$ are the mole fraction solubility of the compound $i$, the temperature, the pressure and the ideal gas constant, respectively. These thermodynamic properties were calculated for the systems $\left[\mathrm{C}_{4} \mathrm{C}_{1} \mathrm{Im}\right]\left[\mathrm{C}_{4} \mathrm{~F}_{9} \mathrm{SO}_{3}\right]+$ water and $\left[\mathrm{C}_{10} \mathrm{C}_{1} \mathrm{Im}\right]\left[\mathrm{C}_{4} \mathrm{~F}_{9} \mathrm{SO}_{3}\right]+$ water and reported in Table $\mathrm{S} 2$ of SI together with the results obtained in previous works [21] in order to obtain general trends.

The solubility of the water in the FIL-rich phase was linearly correlated with temperature and the molar enthalpies at $T=298.15 \mathrm{~K}$ show that the solubilization of the water in FILs is an endothermic process. Furthermore, the results demonstrate that the largest entropic contribution are obtained for the largest length of alkyl chain in the imidazolium cation, as expected.

On the other hand, the standard molar enthalpy of solution, $\Delta_{\text {sol }} H_{m}^{0}$, presents two mainly contributions: i) the standard molar enthalpy of solvation, $\Delta_{\text {svt }} H_{m}^{0}$; and ii) the standard molar enthalpy of vaporization of the solute, $\Delta_{1}^{\mathrm{g}} H_{m}^{0}$, [21]:

$$
\Delta_{\mathrm{sol}} H_{m}^{0}=\Delta_{\mathrm{svt}} H_{m}^{0}+\Delta_{1}^{\mathrm{g}} H_{m}^{0}
$$

Moreover, considering the scaled particle theory, solvation process can be separated in two different steps at the molecular level. Firstly, a cavity should be available in the solvent to the solute can be incorporated, establishing the corresponding interactions. Then, the enthalpy of solution is controlled by the solute-solvent and solute-solute interactions, whereas the enthalpy of solvation depends on the formation of the cavity and is only controlled by solute-solvent interactions [28].

According to the hypothetical reference state for the water at the pressure $\mathrm{p}^{0}=10^{5} \mathrm{~Pa}$ in the gas phase, the standard molar Gibbs free energy of solvation, $\Delta_{\mathrm{svt}} G_{m}^{0}$, can be determined as [29]:

$$
\begin{aligned}
& \Delta_{\mathrm{svt}} G_{m}^{0}=\Delta_{\mathrm{sol}} G_{m}^{0}+R T \ln \left(\frac{p(s 2, T)}{p^{0}}\right) \\
& \Delta_{\mathrm{svt}} S_{m}^{0}=\frac{\Delta_{\mathrm{svt}} H_{m}^{0}-\Delta_{\mathrm{svt}} G_{m}^{0}}{T}
\end{aligned}
$$

where the value of $p(\mathrm{~s} 2, T)$ is $3200 \mathrm{~Pa}$ and corresponds to the vapour pressure of the water at $T=$ $298.15 \mathrm{~K}$. Besides, the standard molar enthalpy of vaporization for the water $\left(\Delta_{1} H_{m}^{0}\right)$ at $T=298.15 \mathrm{~K}$ was considered $43.99 \mathrm{~kJ} \cdot \mathrm{mol}^{-1}$ [30]. Taking into account these data, the conventional standard Gibbs 
energy, molar enthalpy and entropy of solvation were calculated at $T=298.15 \mathrm{~K}$ and reported in Table S3 of SI (data at $T=298.15 \mathrm{~K}$ were extrapolated for the systems where these data were not experimentally determined).

In these studies, the solvation is considered at a macroscopic level. Another approach based on statistical mechanic methods was proposed by Ben-Naim to define a standard state [31]. Then, the changes that occur in the solute vicinity along the dissolution process, for a composition at a constant pressure and temperature, are described by the molar local standard enthalpy, $\Delta_{\mathrm{svt}} H_{m}^{*}(T)$, the local standard Gibbs energy, $\Delta_{\text {svt }} G_{m}^{*}(T)$, and the molar local standard entropy, $\Delta_{\mathrm{svt}} S_{m}^{*}(T)$, of solvation. These standard thermodynamic properties are related to the conventional thermodynamic properties applying the following expressions:

$\Delta_{\mathrm{svt}} G_{m}^{*}=\Delta_{\mathrm{svt}} G_{m}^{0}-R T \ln \left(\frac{R T}{p^{0} V_{j, m}}\right)$

$\Delta_{\mathrm{svt}} H_{m}^{*}=\Delta_{\mathrm{svt}} H_{m}^{0}-R T\left(T \alpha_{\mathrm{j}}-1\right)$

$\Delta_{\mathrm{svt}} S_{m}^{*}=\Delta_{\mathrm{svt}} S_{m}^{0}+R \ln \left(\frac{R T}{p^{0} V_{\mathrm{j}, \mathrm{m}}}\right)-R\left(T \alpha_{\mathrm{j}}-1\right)$

where $V_{\mathrm{j}, \mathrm{m}}$ and $\alpha_{\mathrm{j}}$ are the molar volume of the solvent $\mathrm{j}$ and the isobaric thermal expansibility coefficient of the solvent, respectively, and were calculated from experimental density data [23].

These standard thermodynamic properties are reported in Table S3 of SI and allow a direct comparison between the entropic and enthalpic contribution to the Gibbs free energy of solvation such as is illustrated in Fig. 3. This comparison demonstrated that the contribution for the solvation and solution process in mainly enthalpic. Despite this fact, the entropic contribution is significant (comparison carried out in absolute value). Then, the solvation and solution processes are mainly controlled by the interactions between FILs and water. Furthermore, these results show that both thermodynamic parameters (molar local standard properties of solvation and conventional properties of solution) decrease with the increment of the hydrogenated alkyl chain length in the imidazolium 
cation. The solvation process is spontaneous and favourable because the Gibbs free energy of solvation reported in Table S3 of SI is always negative.

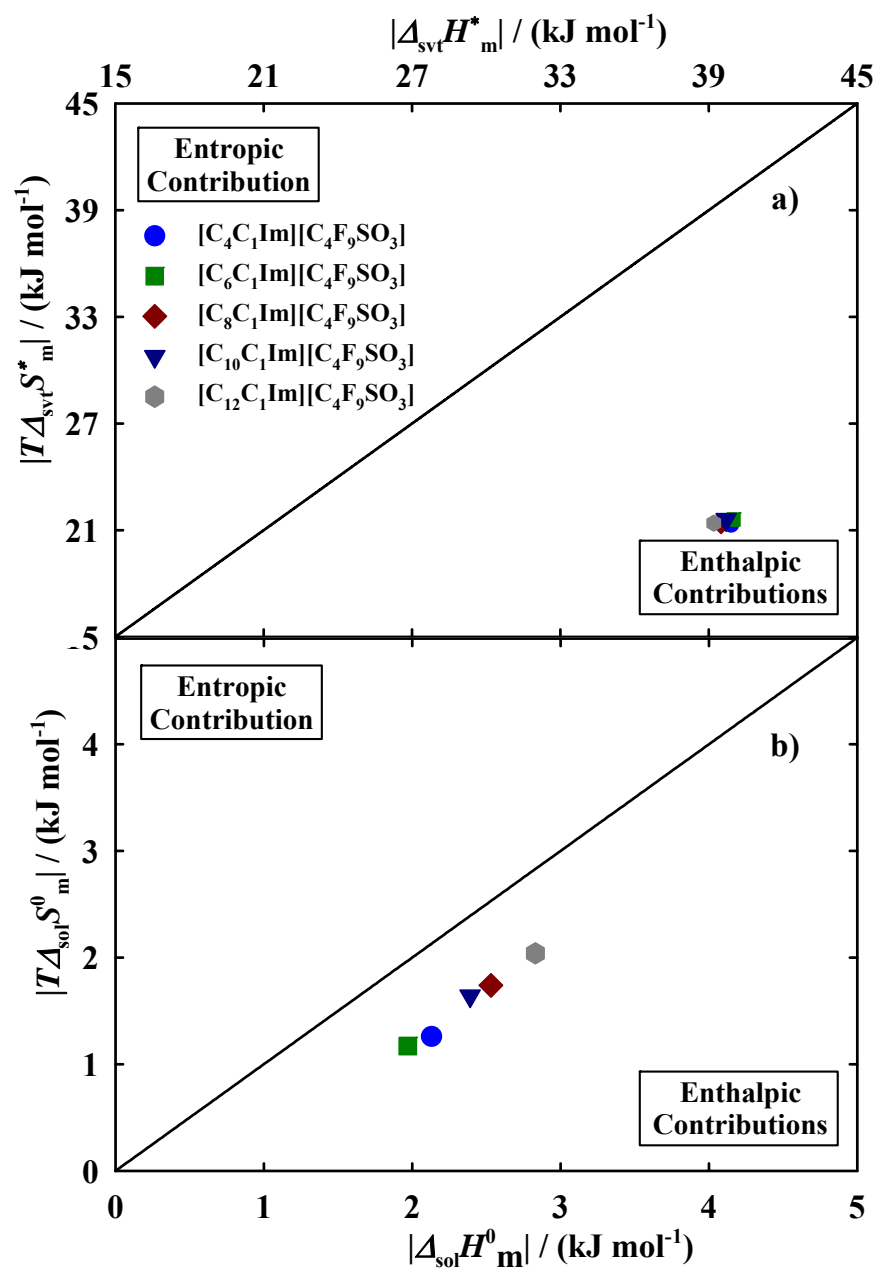

Fig. 3. Thermodynamic properties of: a) solvation and b) solution of water in FILs at $T=298.15 \mathrm{~K}$ for FILs studied in this work $\left(\left[\mathrm{C}_{4} \mathrm{C}_{1} \mathrm{Im}\right]\left[\mathrm{C}_{4} \mathrm{~F}_{9} \mathrm{SO}_{3}\right]\right.$ and $\left.\left[\mathrm{C}_{10} \mathrm{C}_{1} \mathrm{Im}\right]\left[\mathrm{C}_{4} \mathrm{~F}_{9} \mathrm{SO}_{3}\right]\right)$ and those ones previously published $\left(\left[\mathrm{C}_{6} \mathrm{C}_{1} \mathrm{Im}\right]\left[\mathrm{C}_{4} \mathrm{~F}_{9} \mathrm{SO}_{3}\right]\right.$, $\left[\mathrm{C}_{8} \mathrm{C}_{1} \mathrm{Im}\right]\left[\mathrm{C}_{4} \mathrm{~F}_{9} \mathrm{SO}_{3}\right]$ and $\left.\left[\mathrm{C}_{12} \mathrm{C}_{1} \mathrm{Im}\right]\left[\mathrm{C}_{4} \mathrm{~F}_{9} \mathrm{SO}_{3}\right]\right)[21]$.

\subsection{Aggregation Behaviour}

Measurements of ionic conductivity against FIL concentration at $T=298.15 \mathrm{~K}$ were measured for $\left[\mathrm{C}_{2} \mathrm{C}_{1} \mathrm{Im}\right]\left[\mathrm{C}_{4} \mathrm{~F}_{9} \mathrm{CO}_{2}\right], \quad\left[\mathrm{C}_{4} \mathrm{C}_{1} \mathrm{Im}\right]\left[\mathrm{C}_{4} \mathrm{~F}_{9} \mathrm{SO}_{3}\right], \quad\left[\mathrm{C}_{10} \mathrm{C}_{1} \mathrm{Im}\right]\left[\mathrm{C}_{4} \mathrm{~F}_{9} \mathrm{SO}_{3}\right], \quad\left[\mathrm{N}_{1112(\mathrm{OH})}\right]\left[\mathrm{C}_{4} \mathrm{~F}_{9} \mathrm{CO}_{2}\right] \quad$ and $\left[\mathrm{N}_{1112(\mathrm{OH})}\right]\left[\mathrm{C}_{8} \mathrm{~F}_{17} \mathrm{SO}_{3}\right]$. An example of these measurements is illustrated in Fig. S1 of SI. The corresponding critical aggregation concentrations (CACs) were determined using Phillips definition and are depicted in Fig. 4, Table 2 and Table S4. The CAC can be determined using the slope depicted in the plots of conductivity $v$ FIL concentration. The $1^{\text {st }}$ transition is present in all tested FILs and is 
correspondent to the critical micelle concentration presents in the traditional surfactants. For the completely water miscible FILs, $\left[\mathrm{C}_{2} \mathrm{C}_{1} \mathrm{Im}\right]\left[\mathrm{C}_{4} \mathrm{~F}_{9} \mathrm{CO}_{2}\right]$ and $\left[\mathrm{N}_{1112(\mathrm{OH})}\right]\left[\mathrm{C}_{4} \mathrm{~F}_{9} \mathrm{CO}_{2}\right]$, two more transitions are observed which corresponds to the $2^{\text {nd }}$ and $3^{\text {rd }}$ CACs, and these values are shown in Table S4. These transitions are related to total water solubility of these FILs and are associated to the presence of different structures with the increment of the FIL concentration.

The FILs families studied in this work, with only 4 carbon atoms in the perfluorinated alkyl chain $\left(\left[\mathrm{C}_{4} \mathrm{~F}_{9} \mathrm{SO}_{3}\right]^{-}\right)$, improve the surfactant power of conventional perfluorosurfactants with 8 carbon atoms and the corresponding hydrogenated counterparts (see Fig. 4a) [32-34] where the lowest critical micellar concentration corresponds to the highest surfactant power. This fact corroborates that this specific IL family improves the surfactant performance of the commercial surfactants used nowadays for industrial applications. Fig. $4 \mathrm{~b}$ illustrates the influence of the hydrogenated alkyl chain length on the surfactant behaviour by the study of the $\left[\mathrm{C}_{n} \mathrm{C}_{1} \mathrm{Im}\right]\left[\mathrm{C}_{4} \mathrm{~F}_{9} \mathrm{SO}_{3}\right]$ family, with lower $\mathrm{CAC}$ values achieved with the increment of $\mathrm{n}$ from 2 to 12 . An even higher improvement is achieved with longer fluorinated alkyl chains with 8 carbon $\left(\left[\mathrm{C}_{8} \mathrm{~F}_{17} \mathrm{SO}_{3}\right]^{-}\right)$atoms as demonstrated in Fig. $4 \mathrm{c}$ and Table 2 for the cholinium-based FILs with a CAC value of $1.87 \mathrm{mmol} \mathrm{kg}^{-1}$ for the longer fluorinated anion $\left(\left[\mathrm{C}_{8} \mathrm{~F}_{17} \mathrm{SO}_{3}\right]^{-}\right)$, in comparison to the value of $16.1 \mathrm{mmol}^{-1}$ when a short fluorinated chain $\left(\left[\mathrm{C}_{4} \mathrm{~F}_{9} \mathrm{SO}_{3}\right]^{-}\right)$is conjugated to the same cation [22]. The same trend was verified by comparing the results achieved in this work with cholinium perfluoropentanoate $\left(\left[\mathrm{N}_{1112(\mathrm{OH})}\right]\left[\mathrm{C}_{4} \mathrm{~F}_{9} \mathrm{CO}_{2}\right]\right)$, with literature values for cholinium perfluorooctanoate $\left(\left[\mathrm{N}_{1112(\mathrm{OH})}\right]\left[\mathrm{C}_{8} \mathrm{~F}_{17} \mathrm{CO}_{2}\right]\right)$, were the $\mathrm{CAC}$ values decrease from 9.27 to $1.0 \mathrm{mmol} \mathrm{kg}^{-1}$, respectively [35]. Considering these experimental results, the increment of both hydrogenated and fluorinated side-chain is directly related to lower CAC values.

The imidazolium-based FIL $\left(\left[\mathrm{C}_{2} \mathrm{C}_{1} \mathrm{Im}\right]\left[\mathrm{C}_{4} \mathrm{~F}_{9} \mathrm{SO}_{3}\right]\right)$ shows $\mathrm{CAC}$ values slightly lower than the cholinium cation $\left(\left[\mathrm{N}_{1112(\mathrm{OH})}\right]\left[\mathrm{C}_{4} \mathrm{~F}_{9} \mathrm{SO}_{3}\right]\right)\left(14.6\right.$ and $16.1 \mathrm{mmol} \mathrm{kg}^{-1}$, respectively). An opposite behaviour is observed with the perfluoropentanoate anion where $\left[\mathrm{N}_{1112(\mathrm{OH})}\right]\left[\mathrm{C}_{4} \mathrm{~F}_{9} \mathrm{CO}_{2}\right]$ has lower $\mathrm{CAC}$ value than the imidazolium cation, $\left[\mathrm{C}_{2} \mathrm{C}_{1} \mathrm{Im}\right]\left[\mathrm{C}_{4} \mathrm{~F}_{9} \mathrm{CO}_{2}\right],\left(9.27\right.$ and $21.0 \mathrm{mmol} \mathrm{kg}^{-1}$, 
respectively). The increment of the fluorinated chain length results in similar CAC values obtained for either $\left[\mathrm{N}_{1112(\mathrm{OH})}\right]\left[\mathrm{C}_{8} \mathrm{~F}_{17} \mathrm{SO}_{3}\right],\left[\mathrm{N}_{1112(\mathrm{OH})}\right]\left[\mathrm{C}_{8} \mathrm{~F}_{17} \mathrm{CO}_{2}\right][35]$ and $\left[\mathrm{C}_{2} \mathrm{C}_{1} \mathrm{Im}\right]\left[\mathrm{C}_{8} \mathrm{~F}_{17} \mathrm{SO}_{3}\right][22](1.87,1.0$ and $1.33 \mathrm{mmol} \mathrm{kg}^{-1}$, respectively) suggesting a major influence of the chain length in the aggregation behaviour.
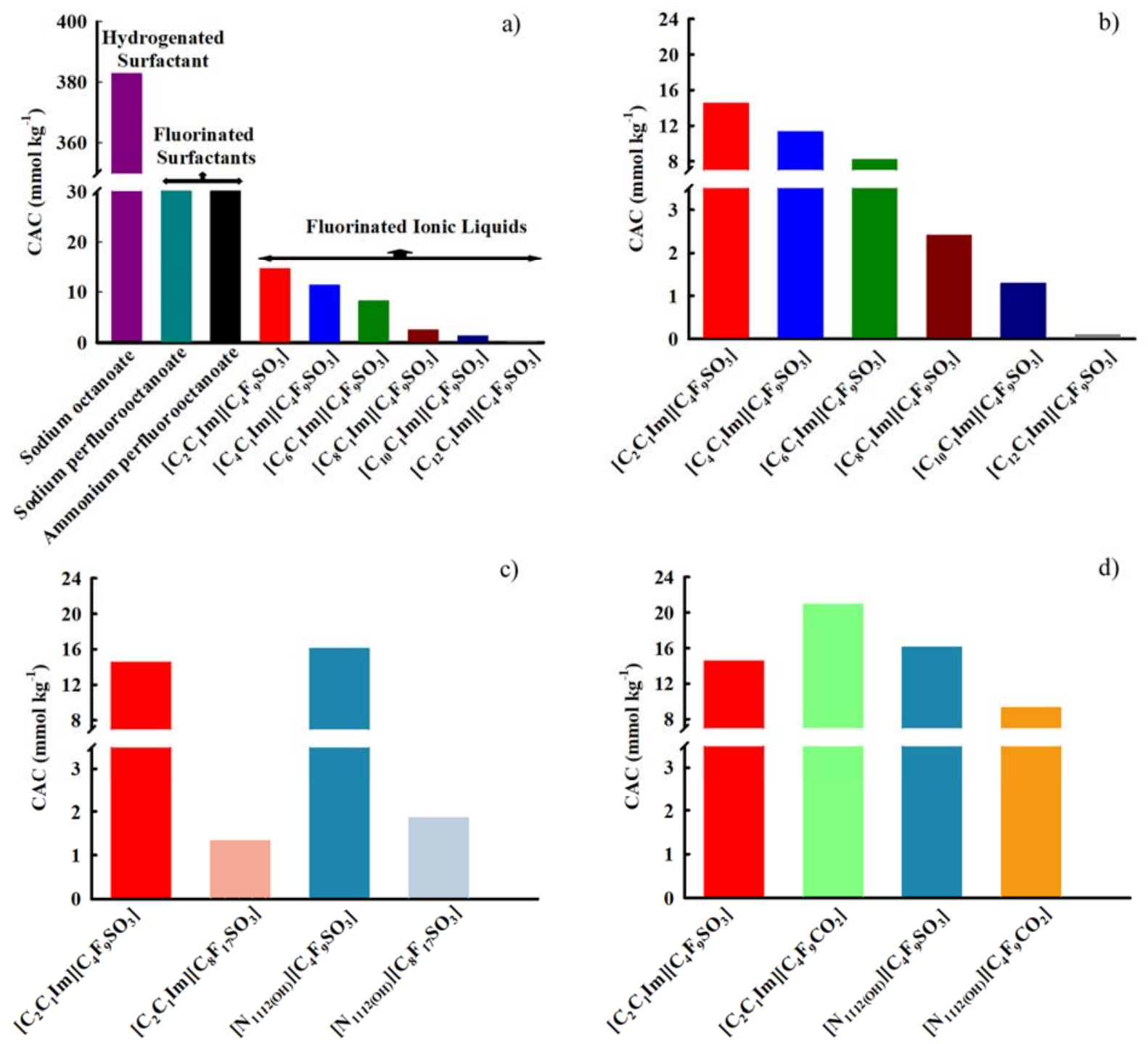

Fig. 4. Critical aggregation concentration (CAC) values of: a) traditional surfactants [32-34] and $\left[\mathrm{C}_{n} \mathrm{C}_{1} \mathrm{Im}\right]\left[\mathrm{C}_{4} \mathrm{~F}_{9} \mathrm{SO}_{3}\right]$ family; b) the $\left[\mathrm{C}_{\mathrm{n}} \mathrm{C}_{1} \mathrm{Im}\right]\left[\mathrm{C}_{4} \mathrm{~F}_{9} \mathrm{SO}_{3}\right]$ family where: $\left[\mathrm{C}_{4} \mathrm{C}_{1} \mathrm{Im}\right]\left[\mathrm{C}_{4} \mathrm{~F}_{9} \mathrm{SO}_{3}\right]$ and $\left[\mathrm{C}_{10} \mathrm{C}_{1} \mathrm{Im}\right]\left[\mathrm{C}_{4} \mathrm{~F}_{9} \mathrm{SO}_{3}\right]$ were studied in this work and $\left[\mathrm{C}_{2} \mathrm{C}_{1} \mathrm{Im}\right]\left[\mathrm{C}_{4} \mathrm{~F}_{9} \mathrm{SO}_{3}\right],\left[\mathrm{C}_{6} \mathrm{C}_{1} \mathrm{Im}\right]\left[\mathrm{C}_{4} \mathrm{~F}_{9} \mathrm{SO}_{3}\right],\left[\mathrm{C}_{8} \mathrm{C}_{1} \mathrm{Im}\right]\left[\mathrm{C}_{4} \mathrm{~F}_{9} \mathrm{SO}_{3}\right]$ and $\left[\mathrm{C}_{12} \mathrm{C}_{1} \mathrm{Im}\right]\left[\mathrm{C}_{4} \mathrm{~F}_{9} \mathrm{SO}_{3}\right]$ were previously published $[21,22]$; c) FILs based on perfluorobutanesulfonate and perfluoroctanesulfonate anions conjugated with $\left[\mathrm{C}_{2} \mathrm{C}_{1} \mathrm{Im}\right]^{+}$and $\left[\mathrm{N}_{1112(\mathrm{OH})}\right]^{+}$cations; d) FILs based on perfluorobutanesulfonate and perfluoropentanoate anions conjugated with $\left[\mathrm{C}_{2} \mathrm{C}_{1} \mathrm{Im}\right]^{+}$and $\left[\mathrm{N}_{1112(\mathrm{OH})}\right]^{+}$cations. 
Table 2

Critical aggregation concentration, CAC, ionization degree, $\alpha$, and Gibbs free energy of aggregation, $\Delta G_{\text {agg }}^{0}$, determined by conductometry at $T=298.15 \mathrm{~K}$ for FILs in aquec solutions.

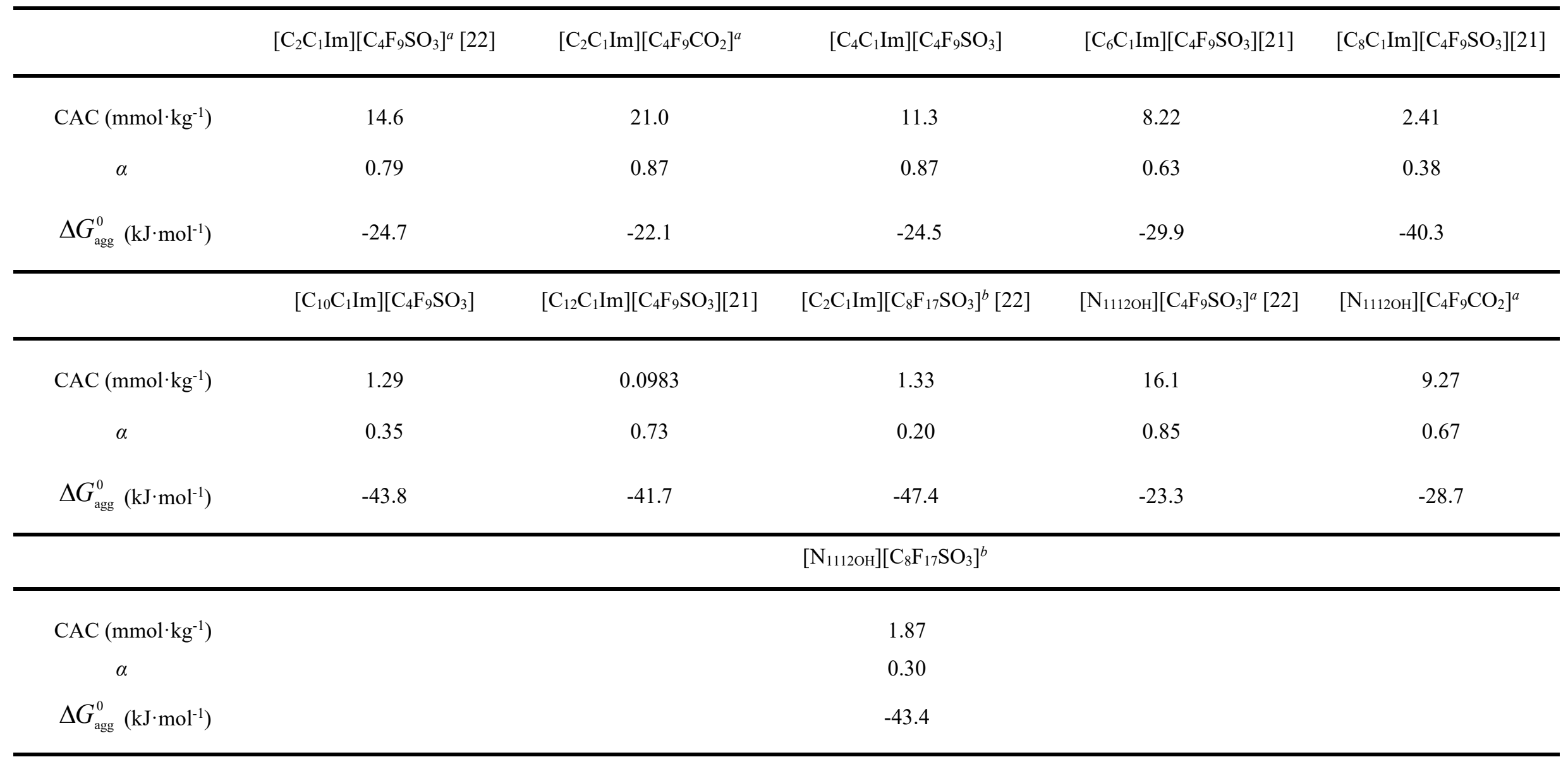

${ }^{a}$ Data of $2^{\text {nd }}$ and $3^{\text {rd }} \mathrm{CAC}$ are included in supporting information.

${ }^{b}$ Data of the $2^{\text {nd }}$ and $3^{\text {rd }} \mathrm{CAC}$ are not included as a result of their high viscosity which limits the experimental method. 
The degree of ionization of the aggregates, $\alpha$, was also evaluated in this work. This parameter is related to the fraction of charges of surfactant ions in the micelle neutralized by micelle-bound counterions. The ions of these surfactants are completely dissociated in aqueous solutions. However, they are partly associated with counterions when forming their aggregates [22]. The degree of ionization of these aggregates can be calculated from the ratio of the slopes of the linear fragments above and below the CAC concentration. These values are presented in Table 2 for the studied FILs. A lower value of $\alpha$ indicates a better packed micelle. On the other hand, the degree of counterion binding or counterions condensed on the micellar interface, $\beta$, was also determined though the relationship:

$$
\beta=1-\alpha
$$

This parameter is related to the size of the aggregate, the charge density at the aggregate surface, and the hydrophobic nature of the counterions. FILs with long chains can form bulkier aggregates and better packed structures, comparatively to FILs with small chain lengths. Then, the number of ions per aggregate and the ion volume per surfactant and the volume per surfactant ion in the case of FILs based on $\left[\mathrm{C}_{8} \mathrm{~F}_{17} \mathrm{SO}_{3}\right]^{-}$anion are higher. Moreover, the polar headgroups of these FILs are packed more closely neutralizing a larger fraction of counterions. For the $\left[\mathrm{C}_{\mathrm{n}} \mathrm{C}_{1} \mathrm{Im}\right]\left[\mathrm{C}_{4} \mathrm{~F}_{9} \mathrm{SO}_{3}\right]$ family, the $\alpha$ values decrease and $\beta$ values increase with the increment of the hydrogenated alkyl chain up to a decyl ( $\mathrm{n}=10),\left(\left[\mathrm{C}_{12} \mathrm{C}_{1} \mathrm{Im}\right]\left[\mathrm{C}_{4} \mathrm{~F}_{9} \mathrm{SO}_{3}\right]\right.$ does not follow this trend) [21]. This result may be related to the major contribution of the hydrogenated alkyl chain in the aggregation process than in the other imidazolium-based cations, where the fluorinated domain may be equally contributing to the aggregation. Then, the packing process may origin better packed micelles. The same tendency was verified for both $\left[\mathrm{C}_{2} \mathrm{C}_{1} \mathrm{Im}\right]^{+}$and $\left[\mathrm{N}_{1112(\mathrm{OH})}\right]^{+}$cations with the increment of the fluorinated chain from $\left[\mathrm{C}_{4} \mathrm{~F}_{9} \mathrm{SO}_{3}\right]^{-}$to $\left[\mathrm{C}_{8} \mathrm{~F}_{17} \mathrm{SO}_{3}\right]$. The influence of both cation and anion core is not so evidenced. When we compare the same anion conjugated with either cholinium or 1-ethyl-3-methylimidazolium cations, it is possible to conclude that for the perfluoropentanoate-based anion the $\alpha$ value is lower 
for the cholinium-based FIL, than for the imidazolium-based FIL. However, an opposite trend is verified when the same cations are conjugated with the perfluorobutanesulfonate anion.

The standard Gibbs free energy of the aggregation process, $\Delta G_{\text {agg }}^{0}$, was calculated considering the pseudophase model of micellization [36]:

$$
\Delta G_{a g g}^{0}=R T(1+\beta) \ln x_{\mathrm{CAC}}
$$

where the $R, T$ and $x_{\mathrm{CAC}}$ are the universal gas constant, absolute temperature and the critical micellar concentration expressed in mole fraction, respectively. Table 2 lists standard free energies of the aggregation process for the FILs studied in this work and includes values for other FILs taken from the literature [21,22]. The standard Gibbs free energy of aggregation quantifies the free energy difference per mole between FIL monomers in aqueous solutions and in the aggregates formed. Negative values for this parameter indicate spontaneous aggregation of these surfactants. Considering the values here reported, the aggregation process is always spontaneous for all studied compounds. Additionally, an increment on the hydrogenated and fluorinated alkyl side chain length presents lower values of standard Gibbs free energy, meaning that these bulkier FILs have a facilitated aggregation process.

\subsection{Surface Properties and Critical Packing Parameters}

The surface tension of the different families of FILs herein studied were measured in aqueous solutions at $T=298.15 \mathrm{~K}$ to evaluate their surface activities, in order to better understand their selfaggregation behaviour. Fig. 5 illustrate these experimental measurements for $\left[\mathrm{C}_{6} \mathrm{C}_{1} \mathrm{Im}\right]\left[\mathrm{C}_{4} \mathrm{~F}_{9} \mathrm{SO}_{3}\right]$, $\left[\mathrm{C}_{8} \mathrm{C}_{1} \mathrm{Im}\right]\left[\mathrm{C}_{4} \mathrm{~F}_{9} \mathrm{SO}_{3}\right], \quad\left[\mathrm{C}_{12} \mathrm{C}_{1} \mathrm{Im}\right]\left[\mathrm{C}_{4} \mathrm{~F}_{9} \mathrm{SO}_{3}\right], \quad\left[\mathrm{C}_{2} \mathrm{C}_{1} \mathrm{Im}\right]\left[\mathrm{C}_{4} \mathrm{~F}_{9} \mathrm{CO}_{2}\right], \quad\left[\mathrm{N}_{1112(\mathrm{OH})}\right]\left[\mathrm{C}_{4} \mathrm{~F}_{9} \mathrm{SO}_{3}\right]$, $\left[\mathrm{N}_{1112(\mathrm{OH})}\right]\left[\mathrm{C}_{4} \mathrm{~F}_{9} \mathrm{CO}_{2}\right], \quad\left[\mathrm{C}_{2} \mathrm{C}_{1} \mathrm{Im}\right]\left[\mathrm{C}_{8} \mathrm{~F}_{17} \mathrm{SO}_{3}\right]$, and $\left[\mathrm{N}_{1112(\mathrm{OH})}\right]\left[\mathrm{C}_{8} \mathrm{~F}_{17} \mathrm{SO}_{3}\right]$ (a comparison with $\left[\mathrm{C}_{2} \mathrm{C}_{1} \mathrm{Im}\right]\left[\mathrm{C}_{4} \mathrm{~F}_{9} \mathrm{SO}_{3}\right]$, previously published, was also incorporated [22]). 

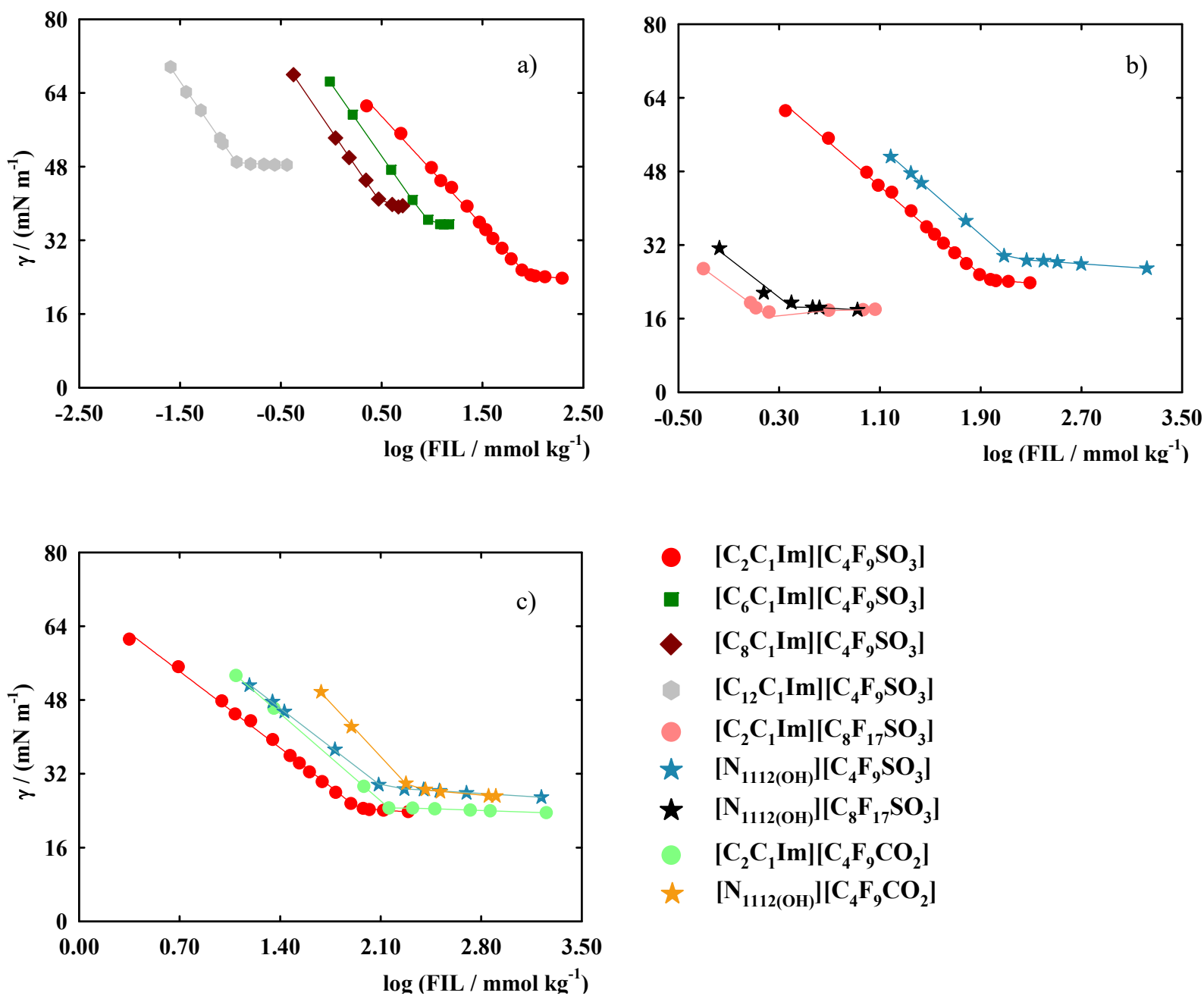

Fig. 5. Surface tension of different concentrations of FILs at $T=298.15 \mathrm{~K}$ as a function of: a) hydrogenated alkyl chain length; b) perfluorobutanesulfonate and perfluoroctanesulfonate anions conjugated with $\left[\mathrm{C}_{2} \mathrm{C}_{1} \operatorname{Im}\right]^{+}$and $\left[\mathrm{N}_{1112(\mathrm{OH})}\right]^{+}$ cations; c) perfluorobutanesulfonate and perfluoropentanoate anions conjugated with $\left[\mathrm{C}_{2} \mathrm{C}_{1} \operatorname{Im}\right]^{+}$and $\left[\mathrm{N}_{1112(\mathrm{OH})}\right]^{+}$cations. Data from literature used for $\left[\mathrm{C}_{2} \mathrm{C}_{1} \mathrm{Im}\right]\left[\mathrm{C}_{4} \mathrm{~F}_{9} \mathrm{SO}_{3}\right][22]$.

The experimental results demonstrate that the incorporation of FIL in aqueous solutions decreases surface energy because these compounds are accumulated in the air/water interface due to the unfavourable interaction between fluorinated alkyl chains and water molecules. The dissolution of FILs ions in the bulk phase take place when the interface is saturated, forming micelles after the CAC. Then, the surface tension after CAC value is approximately constant because these micelles are not surface actives. The breakpoint from these two behaviours corresponds to the CAC value and its surface tension is denoted as $\gamma_{C A C}$. [22] The absence of a minimum around the CAC value demonstrate the high purity of these surfactants. For the $\left[\mathrm{C}_{8} \mathrm{~F}_{17} \mathrm{SO}_{3}\right]^{-}$anion and for the imidazolium- 
based cations with long hydrogenated alkyl chains, this point corresponds to the $1^{\text {st }} \mathrm{CAC}$ observed by conductimetry. However, for the cholinium cation conjugated with the perfluorubutanesulfonate anion and for the other FILs based on the perfluoropentanoate anions, the breakpoint is between the $2^{\text {nd }}$ and $3^{\text {rd }}$ transitions detected by conductimetry (see Table S4), which could be related to the presence of more stable aggregates at these concentrations.

From these experimental results, the maximum surface excess concentration, $\Gamma_{\max }$, was calculated considering the Gibbs adsorption isotherm: [37]

$$
\Gamma_{\max }=-\frac{1}{2.303 n R T}\left(\frac{\mathrm{d} \gamma}{\mathrm{d} \log \mathrm{C}}\right)_{T}
$$

where $n, R, T$ and $C$ are the number of species in solution, the universal gas constant, the absolute temperature and the concentration of FIL, respectively. The $n$ parameter was determined as $n=2-$ $\alpha$ for the ionic surfactants. [37] Then, the minimum area occupied per surfactant at the interface, $A_{\min }$, was calculated as:

$$
A_{\min }=\frac{10^{18}}{N_{\mathrm{A}} \Gamma_{\max }}
$$

where $N_{\mathrm{A}}$ is number of Avogadro. High values of $\Gamma_{\max }$ or the corresponding small $A$ min correspond to a denser arrangement of these molecules at the interface. The effectiveness of the surface tension reduction, ПСAC, can be calculated as follow:

$\Pi_{\mathrm{CAC}}=\gamma_{0}-\gamma_{C A C}$

where $\gamma_{0}$ and $\gamma_{C A C}$ are the surface tension of water and the surface tension of the solution at CAC, respectively. These values are related to the maximum reduction of surface tension that occurs by the dissolution of these molecules and its capacity to reduce the surface tension of these solutions. Using these parameters, the standard free energies of adsorption, $\Delta G_{a d}^{0}$, was determined as follow:

$\Delta G_{a d}^{0}=\Delta G_{a g g}^{0}-\frac{\Pi_{\mathrm{CAC}}}{\Gamma_{\max }}$ 
The surface parameters calculated from surface tension measurements are shown in Table 3. The $\Delta G_{a d}^{0}$ values are bigger than the $\Delta G_{a g g}^{0}$ values for all FILs which demonstrate that the adsorption process is more spontaneous than the aggregation process. The shape and the structure of these aggregates were predicted using the critical packing parameter, $P,[38]$ which is defined as:

$P=\frac{V_{0}}{A_{\min } l_{\mathrm{c}}}$

where $l_{\mathrm{c}}$ and $V_{0}$ are the maximum effective length and the effective volume occupied by hydrophobic chains in the aggregate core, respectively. The shape of the aggregates can be considered spherical for $P \leq 0.33$, cylindrical for $P \leq 0.5$, lamellar for $P \leq 1$ or inverted structures for $P>1$.

Modifications of Tanford equations [39] to fluorinated compounds were used to determine the volume, $V_{0}$, and the length, $l_{c},[40-42]$ as follow:

$V_{0}\left(\mathrm{~nm}^{3}\right)=0.0545+0.0380\left(n_{\mathrm{c}}-1\right) \quad V_{0}\left(\mathrm{~nm}^{3}\right)=0.0545+0.0380\left(n_{\mathrm{c}}-1\right)$

or

$V_{0}\left(\mathrm{~nm}^{3}\right)=0.0424+0.0416\left(n_{\mathrm{c}}-1\right) \quad l_{\mathrm{c}}(\mathrm{nm})=0.204+0.130\left(n_{\mathrm{c}}-1\right)$

where $n_{\mathrm{c}}$ is the number of carbon atoms in fluorinated chain. The values obtained for the FILs studied in this work are report in Table 4 . These results show that for the anions with small chains $\left(\left[\mathrm{C}_{4} \mathrm{~F}_{9} \mathrm{SO}_{3}\right]^{-}\right.$ and $\left[\mathrm{C}_{4} \mathrm{~F}_{9} \mathrm{CO}_{2}\right]^{-}$) the value of this parameter is between 0.4 and 0.8 for both imidazolium and cholinium-based FILs, which are associated to cylindrical or lamellar micelles. The increment of the hydrogenated alkyl chain length from $\left[\mathrm{C}_{2} \mathrm{C}_{1} \mathrm{Im}\right]\left[\mathrm{C}_{4} \mathrm{~F}_{9} \mathrm{SO}_{3}\right](P=0.439)$ to longer alkyl chains $(P$ between $0.676-0.734$ ) reveals a change on the structure type, from cylindrical to lamellar. For $\left[\mathrm{C}_{2} \mathrm{C}_{1} \mathrm{Im}\right]\left[\mathrm{C}_{8} \mathrm{~F}_{17} \mathrm{SO}_{3}\right]$ and $\left[\mathrm{N}_{1112(\mathrm{OH})}\right]\left[\mathrm{C}_{8} \mathrm{~F}_{17} \mathrm{SO}_{3}\right]$, these values are lower, however, they are both slightly higher than 0.33 which may suggest their aggregation into more spherical structures when the fluorinated chain increase from $\left[\mathrm{C}_{4} \mathrm{~F}_{9} \mathrm{SO}_{3}\right]^{-}$to $\left[\mathrm{C}_{8} \mathrm{~F}_{17} \mathrm{SO}_{3}\right]^{-}$. 


\section{Table 3}

Critical aggregation concentration, CAC, thermodynamic properties of aggregation, surface properties and micellization parameters for Fluorinated Ionic Liquids in aqueous solution determined by surface tension at $T=298.15 \mathrm{~K}$.

\begin{tabular}{|c|c|c|c|c|c|}
\hline & {$\left[\mathrm{C}_{2} \mathrm{C}_{1} \mathrm{Im}\right]\left[\mathrm{C}_{4} \mathrm{~F}_{9} \mathrm{SO}_{3}\right][22]$} & {$\left[\mathrm{C}_{2} \mathrm{C}_{1} \mathrm{Im}\right]\left[\mathrm{C}_{4} \mathrm{~F}_{9} \mathrm{CO}_{2}\right]$} & {$\left[\mathrm{C}_{6} \mathrm{C}_{1} \mathrm{Im}\right]\left[\mathrm{C}_{4} \mathrm{~F}_{9} \mathrm{SO}_{3}\right]$} & {$\left[\mathrm{C}_{8} \mathrm{C}_{1} \mathrm{Im}\right]\left[\mathrm{C}_{4} \mathrm{~F}_{9} \mathrm{SO}_{3}\right]$} & {$\left[\mathrm{C}_{12} \mathrm{C}_{1} \mathrm{Im}\right]\left[\mathrm{C}_{4} \mathrm{~F}_{9} \mathrm{SO}_{3}\right]$} \\
\hline$\gamma_{C A C}\left(\mathrm{mN} \cdot \mathrm{m}^{-1}\right)$ & 24.5 & 24.7 & 36.5 & 40.9 & 48.9 \\
\hline $10^{6} \Gamma_{\max }\left(\mathrm{mol} \cdot \mathrm{m}^{-2}\right)$ & 2.60 & 3.67 & 4.01 & 3.47 & 4.36 \\
\hline$A_{\min }\left(\mathrm{nm}^{2}\right)$ & 0.64 & 0.45 & 0.41 & 0.48 & 0.38 \\
\hline$\Pi_{\mathrm{CAC}}\left(\mathrm{mN} \cdot \mathrm{m}^{-1}\right)$ & 44.4 & 44.1 & 32.4 & 28.0 & 20.0 \\
\hline$\Delta G_{a d}^{0}\left(\mathrm{~kJ} \cdot \mathrm{mol}^{-1}\right)$ & {$\left[\mathrm{C}_{2} \mathrm{C}_{1} \mathrm{Im}\right]\left[\mathrm{C}_{8} \mathrm{~F}_{17} \mathrm{SO}_{3}\right]$} & {$\left[\mathrm{N}_{1112 \mathrm{OH}}\right]\left[\mathrm{C}_{4} \mathrm{~F}_{9} \mathrm{SO}_{3}\right]$} & {$\left[\mathrm{N}_{1112 \mathrm{OH}}\right]\left[\mathrm{C}_{4} \mathrm{~F}_{9} \mathrm{CO}_{2}\right]$} & {$\left[\mathrm{N}_{1112 \mathrm{OH}}\right]\left[\mathrm{C}_{8} \mathrm{~F}_{17} \mathrm{SO}_{3}\right]$} & \\
\hline $\mathrm{CAC}\left(\mathrm{mmol} \cdot \mathrm{kg}^{-1}\right)$ & 1.47 & 131 & 202 & 2.44 & \\
\hline$\gamma_{C A C}\left(\mathrm{mN} \cdot \mathrm{m}^{-1}\right)$ & 17.4 & 29.0 & 28.8 & 18.7 & \\
\hline $10^{6} \Gamma_{\max }\left(\mathrm{mol} \cdot \mathrm{m}^{-2}\right)$ & 1.96 & 3.59 & 5.18 & 2.20 & \\
\hline$\Delta G_{a d}^{0}\left(\mathrm{~kJ} \cdot \mathrm{mol}^{-1}\right)$ & -73.8 & -32.4 & -24.1 & -66.2 & \\
\hline
\end{tabular}


Table 4

Critical packing parameter for FILs in aqueous solutions determined by surface tension at $T=298.15 \mathrm{~K}$.

\begin{tabular}{lcc}
\hline FILs & $P($ Equation 17$)$ & $P($ Equation 18) \\
\hline $\left.\mathrm{C}_{2} \mathrm{C}_{1} \mathrm{Im}\right]\left[\mathrm{C}_{4} \mathrm{~F}_{9} \mathrm{SO}_{3}\right][22]$ & 0.439 & 0.442 \\
{$\left[\mathrm{C}_{2} \mathrm{C}_{1} \mathrm{Im}\right]\left[\mathrm{C}_{4} \mathrm{~F}_{9} \mathrm{CO}_{2}\right]$} & 0.618 & 0.622 \\
{$\left[\mathrm{C}_{6} \mathrm{C}_{1} \mathrm{Im}\right]\left[\mathrm{C}_{4} \mathrm{~F}_{9} \mathrm{SO}_{3}\right]$} & 0.676 & 0.680 \\
{$\left[\mathrm{C}_{8} \mathrm{C}_{1} \mathrm{Im}\right]\left[\mathrm{C}_{4} \mathrm{~F}_{9} \mathrm{SO}_{3}\right]$} & & 0.588 \\
{$\left[\mathrm{C}_{12} \mathrm{C}_{1} \mathrm{Im}\right]\left[\mathrm{C}_{4} \mathrm{~F}_{9} \mathrm{SO}_{3}\right]$} & 0.585 & 0.738 \\
{$\left[\mathrm{C}_{2} \mathrm{C}_{1} \mathrm{Im}\right]\left[\mathrm{C}_{8} \mathrm{~F}_{17} \mathrm{SO}_{3}\right]$} & 0.734 & 0.354 \\
{$\left[\mathrm{~N}_{1112(\mathrm{OH})}\right]\left[\mathrm{C}_{4} \mathrm{~F}_{9} \mathrm{SO}_{3}\right]$} & & 0.608 \\
{$\left[\mathrm{~N}_{1112(\mathrm{OH})}\right]\left[\mathrm{C}_{4} \mathrm{~F}_{9} \mathrm{CO}_{2}\right]$} & 0.333 & 0.396 \\
{$\left[\mathrm{~N}_{1112(\mathrm{OH})}\right]\left[\mathrm{C}_{8} \mathrm{~F}_{17} \mathrm{SO}_{3}\right]$} & & 0.604 \\
\hline
\end{tabular}

These fluorinated-based structures were also analysed with TEM and the results are depicted in Fig. 6, 7 and 8. The shapes are common in conventional fluorinated surfactants where the fluorinated chains are bulkier than the hydrogenated ones [40]. TEM images were obtained for the first time for $\left[\mathrm{C}_{2} \mathrm{C}_{1} \mathrm{Im}\right]\left[\mathrm{C}_{4} \mathrm{~F}_{9} \mathrm{SO}_{3}\right], \quad\left[\mathrm{C}_{6} \mathrm{C}_{1} \mathrm{Im}\right]\left[\mathrm{C}_{4} \mathrm{~F}_{9} \mathrm{SO}_{3}\right], \quad\left[\mathrm{C}_{8} \mathrm{C}_{1} \mathrm{Im}\right]\left[\mathrm{C}_{4} \mathrm{~F}_{9} \mathrm{SO}_{3}\right], \quad\left[\mathrm{C}_{12} \mathrm{C}_{1} \mathrm{Im}\right]\left[\mathrm{C}_{4} \mathrm{~F}_{9} \mathrm{SO}_{3}\right]$, $\left[\mathrm{C}_{2} \mathrm{C}_{1} \mathrm{Im}\right]\left[\mathrm{C}_{4} \mathrm{~F}_{9} \mathrm{CO}_{2}\right], \quad\left[\mathrm{C}_{2} \mathrm{C}_{1} \mathrm{Im}\right]\left[\mathrm{C}_{8} \mathrm{~F}_{17} \mathrm{SO}_{3}\right], \quad\left[\mathrm{N}_{1112(\mathrm{OH})}\right]\left[\mathrm{C}_{4} \mathrm{~F}_{9} \mathrm{SO}_{3}\right], \quad\left[\mathrm{N}_{1112(\mathrm{OH})}\right]\left[\mathrm{C}_{4} \mathrm{~F}_{9} \mathrm{CO}_{2}\right] \quad$ and $\left[\mathrm{N}_{1112(\mathrm{OH})}\right]\left[\mathrm{C}_{8} \mathrm{~F}_{17} \mathrm{SO}_{3}\right]$. The increment of the hydrogenated chain was herein studied and presented in Fig. 6. In this case, the concentrations used in the aqueous solutions were always higher than the CAC determined by surface tension. 

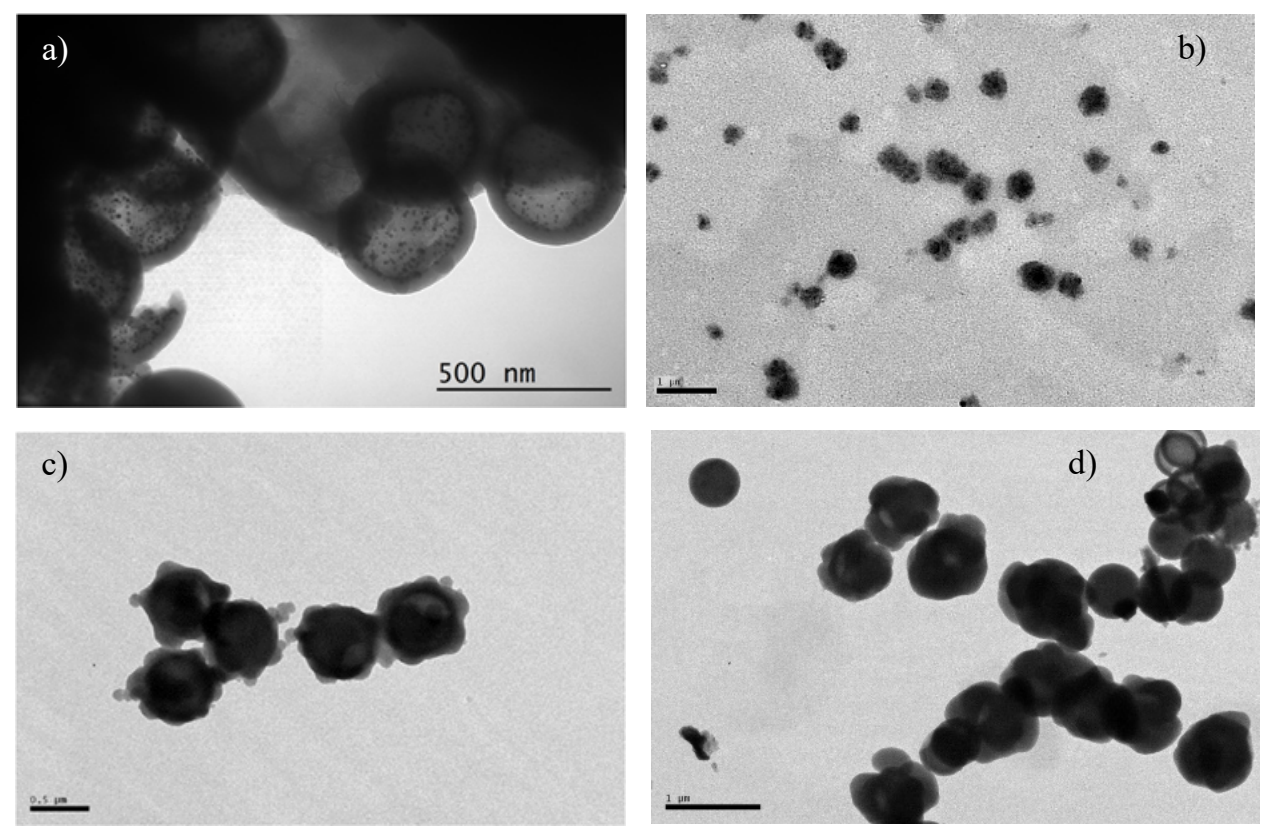

Fig. 6. TEM micrographs for the aggregates in aqueous solutions of: a) $\left[\mathrm{C}_{2} \mathrm{C}_{1} \mathrm{Im}\right]\left[\mathrm{C}_{4} \mathrm{~F}_{9} \mathrm{SO}_{3}\right]$ with a concentration of 3 times of the $\mathrm{CAC}$ value (scale at $0.5 \mu \mathrm{m}$ ); b) $\left[\mathrm{C}_{6} \mathrm{C}_{1} \mathrm{Im}\right]\left[\mathrm{C}_{4} \mathrm{~F}_{9} \mathrm{SO}_{3}\right]$ with a concentration of 2 times the $\mathrm{CAC}$ value (scale at $1 \mu \mathrm{m})$; c) $\left[\mathrm{C}_{8} \mathrm{C}_{1} \mathrm{Im}\right]\left[\mathrm{C}_{4} \mathrm{~F}_{9} \mathrm{SO}_{3}\right]$ with a concentration of 3 times of the $\mathrm{CAC}$ value (scale at $0.5 \mu \mathrm{m}$ ); d) $\left[\mathrm{C}_{12} \mathrm{C}_{1} \mathrm{Im}\right]\left[\mathrm{C}_{4} \mathrm{~F}_{9} \mathrm{SO}_{3}\right]$ with a concentration of 4 times of the $\mathrm{CAC}$ value (scale at $1 \mu \mathrm{m}$ ).

TEM images show that the aggregates size increase with the increment of the alkyl chain length in both hydrogenated (see Fig. 6) and fluorinated chain length (see Fig. 7). For $\left[\mathrm{C}_{2} \mathrm{C}_{1} \mathrm{Im}_{3}\right]\left[\mathrm{C}_{4} \mathrm{~F}_{9} \mathrm{SO}_{3}\right]$ the micellar size is $\approx 0.4 \mu \mathrm{m}$, increasing to $\approx 0.5,0.7$ and $0.8 \mu \mathrm{m}$ for $\left[\mathrm{C}_{6} \mathrm{C}_{1} \mathrm{Im}\right]\left[\mathrm{C}_{4} \mathrm{~F}_{9} \mathrm{SO}_{3}\right]$, $\left[\mathrm{C}_{8} \mathrm{C}_{1} \mathrm{Im}\right]\left[\mathrm{C}_{4} \mathrm{~F}_{9} \mathrm{SO}_{3}\right]$ and $\left[\mathrm{C}_{12} \mathrm{C}_{1} \mathrm{Im}\right]\left[\mathrm{C}_{4} \mathrm{~F}_{9} \mathrm{SO}_{3}\right]$, respectively. The influence of the fluorinated chain length was showed in Fig. 7. For $\left[\mathrm{C}_{2} \mathrm{C}_{1} \mathrm{Im}\right]\left[\mathrm{C}_{4} \mathrm{~F}_{9} \mathrm{SO}_{3}\right]$, the average size of the structures is around 0.4 $\mu \mathrm{m}$, increasing to 0.6 for $\left[\mathrm{C}_{2} \mathrm{C}_{1} \mathrm{Im}\right]\left[\mathrm{C}_{8} \mathrm{~F}_{17} \mathrm{SO}_{3}\right]$. In the cholinium cation, this effect is also evidenced with the average size of the particles, increasing from $0.5 \mu \mathrm{m}$ in $\left[\mathrm{N}_{1112(\mathrm{OH})}\right]\left[\mathrm{C}_{4} \mathrm{~F}_{9} \mathrm{SO}_{3}\right]$ to $0.8 \mu \mathrm{m}$ in $\left[\mathrm{N}_{1112(\mathrm{OH})}\right]\left[\mathrm{C}_{8} \mathrm{~F}_{17} \mathrm{SO}_{3}\right]$. Fig. 8 illustrates the differences in the micellar size between perfluorobutanesulfonate and perfluoropentanoate anion. For both imidazolium and cholinium cation, the structures formed from the perfluorobutanesulfonate anion have a size of approximately 0.4 and $0.5 \mu \mathrm{m}$ respectively, whereas the structures based on the perfluoropentanoate anion present micellar sizes ranging between $0.5-0.6 \mu \mathrm{m}$ for both FILs. 
The cation influence on the micelle size is herein achieved by comparing the cholinium and the imidazolium cation conjugated with both perfluorobutanesulfonate and perfluoropentanoate, with no significant differences achieved for both cases. $\left[\mathrm{C}_{2} \mathrm{C}_{1} \mathrm{Im}\right]\left[\mathrm{C}_{4} \mathrm{~F}_{9} \mathrm{SO}_{3}\right]$ present micelles with the size of $0.4 \mu \mathrm{m}$, whereas $\left[\mathrm{N}_{1112(\mathrm{OH})}\right]\left[\mathrm{C}_{4} \mathrm{~F}_{9} \mathrm{SO}_{3}\right]$ shows structures within the range of $0.5 \mu \mathrm{m}$. The same range of differences were obtained with the perfluoropentanoate anion. These results support that the major influence on the micellar size is driven by the length of both hydrogenated and fluorinated alkyl chain length.
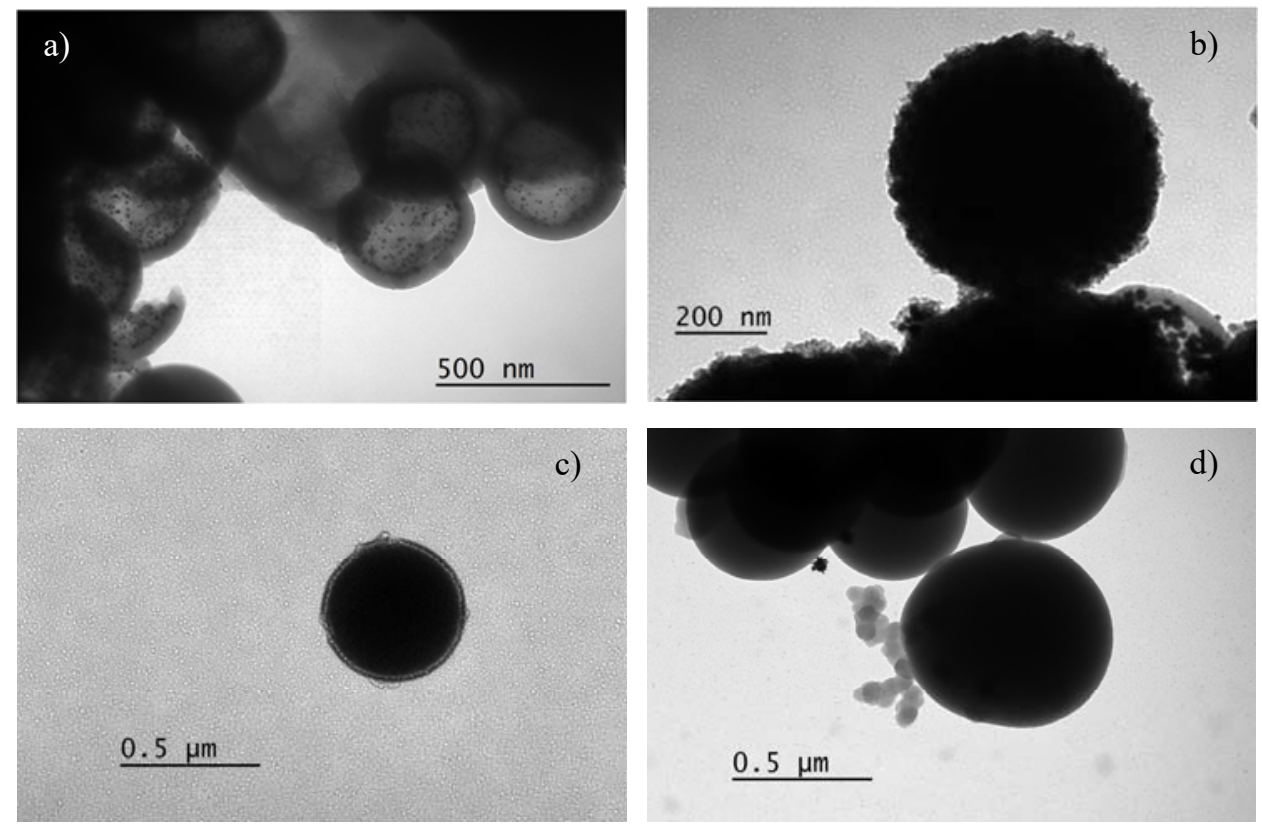

Fig. 7. TEM micrographs for the aggregates in aqueous solutions of: a) $\left[\mathrm{C}_{2} \mathrm{C}_{1} \operatorname{Im}\right]\left[\mathrm{C}_{4} \mathrm{~F}_{9} \mathrm{SO}_{3}\right]$ with a concentration of 3 times the $\mathrm{CAC}$ value (scale at $0.5 \mu \mathrm{m}$ ); b) $\left[\mathrm{C}_{2} \mathrm{C}_{1} \mathrm{Im}\right]\left[\mathrm{C}_{8} \mathrm{~F}_{17} \mathrm{SO}_{3}\right]$ with a concentration of 3 times the $\mathrm{CAC}$ value (scale at $0.2 \mu \mathrm{m}) ; \mathrm{c}$ ) $\left[\mathrm{N}_{1112(\mathrm{OH})}\right]\left[\mathrm{C}_{4} \mathrm{~F}_{9} \mathrm{SO}_{3}\right]$ with a concentration of 2 times the $\mathrm{CAC}$ value (scale at $\left.0.5 \mu \mathrm{m}\right) ; \mathrm{d}$ ) $\left[\mathrm{N}_{1112(\mathrm{OH})}\right]\left[\mathrm{C}_{8} \mathrm{~F}_{17} \mathrm{SO}_{3}\right]$ with a concentration of 2.5 times of the $\mathrm{CAC}$ value (scale at $0.5 \mu \mathrm{m}$ ). 

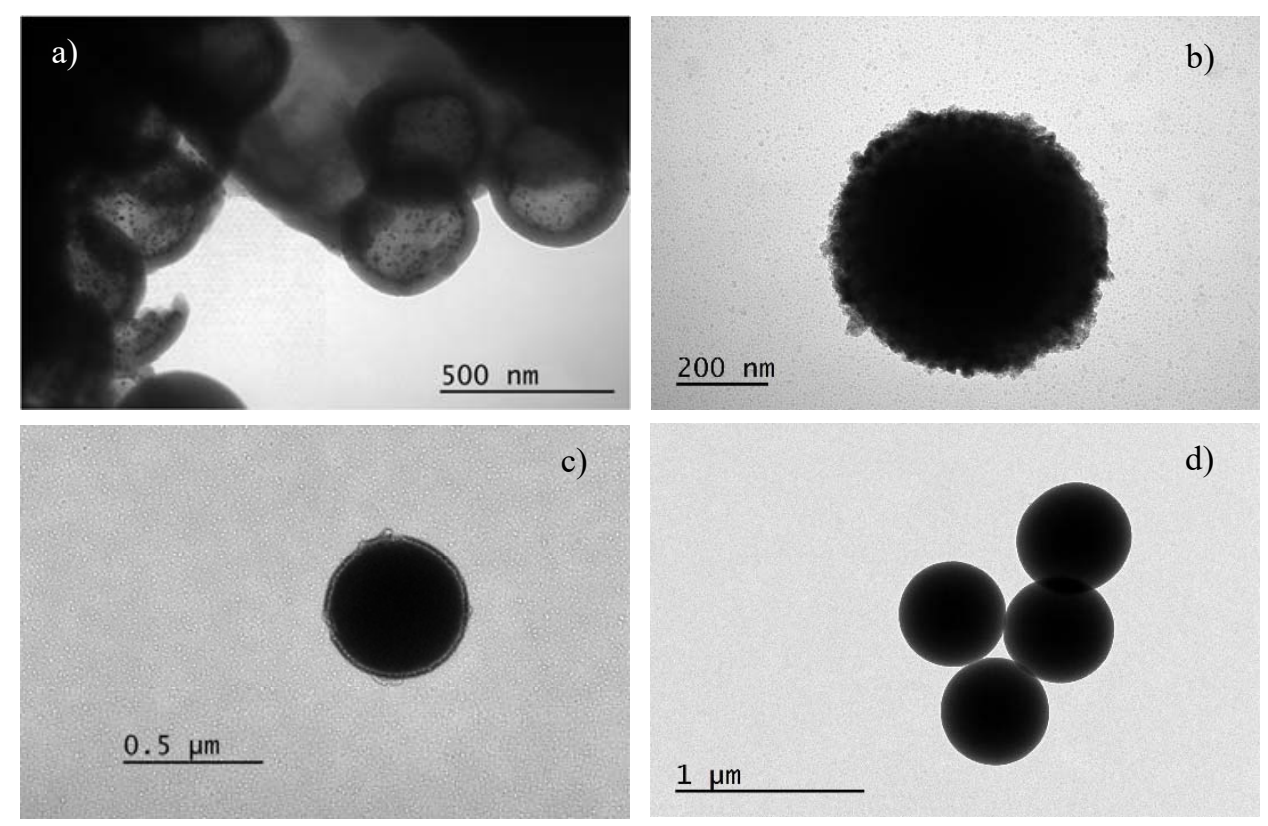

Fig. 8. TEM micrographs for the aggregates in aqueous solutions of: a) $\left[\mathrm{C}_{2} \mathrm{C}_{1} \mathrm{Im}\right]\left[\mathrm{C}_{4} \mathrm{~F}_{9} \mathrm{SO}_{3}\right]$ with a concentration of 3 times of the $\mathrm{CAC}$ value (scale at $0.5 \mu \mathrm{m}$ ); b) $\left[\mathrm{C}_{2} \mathrm{C}_{1} \mathrm{Im}\right]\left[\mathrm{C}_{4} \mathrm{~F}_{9} \mathrm{CO}_{2}\right]$ with a concentration of 2 times the CAC value (scale at $0.2 \mu \mathrm{m})$; c) $\left[\mathrm{N}_{1112(\mathrm{OH})}\right]\left[\mathrm{C}_{4} \mathrm{~F}_{9} \mathrm{SO}_{3}\right]$ with a concentration of 2 times the $\mathrm{CAC}$ value (scale at $\left.0.5 \mu \mathrm{m}\right)$; $\mathrm{d}$ ) $\left[\mathrm{N}_{1112(\mathrm{OH})}\right]\left[\mathrm{C}_{4} \mathrm{~F}_{9} \mathrm{CO}_{2}\right]$ with a concentration of 2 times the $\mathrm{CAC}$ value (scale at $1 \mu \mathrm{m}$ );

\section{Conclusion}

This work aims to fully understand the solubility and phase equilibria of several fluorinated ionic liquids as well as their self-aggregation in aqueous solutions. To accomplish the first objective, the liquid-liquid equilibria of the binary systems FIL + water was analysed using a visual method. The solubility of water in the FIL-rich phase increases with the increment of hydrogenated alkyl chain length in the imidazolium cation. On the other side, the opposite behaviour is observed in the waterrich phase where the increment of the alkyl chain length on imidazolium cation decreases the solubility of FILs in aqueous solutions which could be explained by the increment of the hydrophobic behaviour of these compounds. For longer alkyl chains, the high surfactant behaviour promotes the solubility of these FILs in the water-rich phase. From the thermodynamic analysis it is possible to demonstrate that a largest entropic contribution is obtained for the largest length of alkyl chain in the imidazolium cation, as expected. Furthermore, the contribution for the solvation and solution process is mainly enthalpic and the thermodynamic parameters (molar local standard properties of solvation 
and conventional properties of solution) decrease with the increment of the hydrogenated alkyl chain length in imidazolium cation. Regarding the aggregation behaviour in aqueous solutions obtained through ionic conductivity measurements, the main conclusions are related to a higher surfactant behaviour with longer hydrogenated and fluorinated chain lengths. These conductivity measurements also provide some information regarding the aggregation process, where FILs with long chains can form bulkier aggregates and better packed structures. Moreover, it was also possible to conclude that the aggregation process of all FILs are spontaneous with negative values of standard Gibbs free energy meaning that these bulkier FILs have a facilitated aggregation process.

Considering the results obtained by the surface tension measurement, the incorporation of FILs in aqueous solutions, as well as the increment of the hydrogenated and fluorinated chain length, decreases the surface energy. The surface parameters, calculated from experimental data, demonstrate that the adsorption process is more spontaneous than the aggregation process. The obtained packing parameters proved the influence of the fluorinated chain length in the aggregated structures, where smaller chains are associated to cylindrical or lamellar micelles, and longer fluorinated chains associated to spherical structures. The influence of the hydrogenated and fluorinated chain length on the micellar size was also proved through several structures obtained by TEM.

\section{Acknowledgements}

The authors would like to thank the financial support from FCT/MEC (Portugal), through grant SFRH/BD/100563/2014 (N.S.M.V.) and "Investigador FCT 2014" (IF/00190/2014 to A.B.P and IF/00210/2014 to J.M.M.A.), and projects PTDC/EQU-EQU/29737/2017, PTDC/QEQFTT/3289/2014, IF/00210/2014/CP1244/CT0003. This work was also supported by the Associate Laboratory for Green Chemistry LAQV (financed by national funds from FCT/MCTES (UID/QUI/50006/2019)) and co-financed by the ERDF under the PT2020 Partnership Agreement (POCI-01-0145-FEDER - 007265). 


\section{References}

[1] A. B Lindstrom, M. J. Strynar, E. L Libelo, Polyfluorinated Compounds: Past, Present, and Future, Environ. Sci. Technol. 45 (2011) 7954-7961.

[2] W. T. Tsai, H. P. Chen, W. Y. Hsien, A Review of Uses, Environmental Hazards and Recovery/Recycle Technologies of Perfluorocarbons (PFCs) Emissions from the Semiconductor Manufacturing Processes, J. Loss Prev. Process Ind. 15 (2002) 65-75.

[3] K. Kannan, S. Corsolini, J. Falandysz, G. Fillmann, K. S. Kumar, B. G. Loganathan, M. A. Mohd, J. Olivero, N. Van Wouwe, J. H. Yang, K. M. Aldoust, Perfluorooctanesulfonate and Related Fluorochemicals in Human Blood from Several Countries, Environ. Sci.Technol. 38 (2004) 44894495.

[4] K. Steenland, T. Fletcher,D. A. Savitz, Epidemiologic Evidence on the Health Effects of Perfluorooctanoic Acid (PFOA), Environ. Health Perspect. 118 (2010) 1100-1108.

[5] J. P. Giesy, K. Kannan, Global Distribution of Perfluorooctane Sulfonate in Wildlife, Environ. Sci. Technol. 35 (2001) 1339-1342.

[6] J. P. Giesy, K. Kannan, Perfluorochemical Surfactants in the Environment, Environ. Sci. Technol. $36(2002) 146 \mathrm{~A}-152 \mathrm{~A}$.

[7] K. Kannan, J. Koistinen, K. Beckmen, T. Evans, J. F. Gorzelany, K. J. Hansen, P. D. Jones, E. Helle, M. Nyman, J. P. Giesy, Accumulation of Perfluorooctane Sulfonate in Marine Mammals, Environ. Sci. Technol. 35 (2001) 1593-1598.

[8] U. S. Environmental Protection Agency (US EPA) Preliminary Risk Assessment of the Developmental Toxicity Associated with Exposure to Perfluorooctanoic Acid and Its Salts. US EPA. (2003) OPPT-2003-0012, FRL-7303-8.

[9] X. Lim, The Fluorine Detectives, Nature 566 (2019) 26-29. 
[10] A. B. Pereiro, J. M. M. Araújo, S. Martinho, F. Alves, A. Matias, C. M. M. Duarte, L. P. N. Rebelo, I. M. Marrucho, Fluorinated Ionic Liquids: Properties and Applications, ACS Sustaintable Chem. Eng. 1 (2013) 427-439.

[11] M. J. P. de Melo, A. M. A. Dias, M. Blesic, L. P. N. Rebelo, L. F. Vega, J. A. P. Coutinho, I. M. Marrucho, Liquid-Liquid Equilibrium of (Perfluoroalkane plus Alkane) Binary Mixtures, Fluid Phase Equilib. 242 (2006) 210-219.

[12] A. B. Pereiro, M. J. Pastoriza-Gallego, K. Shimizu, I. M. Marrucho, J. N. C. Lopes, M. M. Pineiro, L. P. N. Rebelo, On the Formation of a New, Third, Nanostructured Domain in Ionic Liquids, J. Phys. Chem. B 117 (2013) 10826-10833.

[13] N. V. Plechkova, K. R. Seddon, Applicatons of Ionic Liquids in the Chemical Industry, Chem. Soc. Rev. 37 (2008) 123-150.

[14] T. L. Merrigan, E. D. Bates, S. C. Dorman, Jr. J. H. Davis, New Fluorous Ionic Liquids Function as Surfactants in Conventional Room-temperature Ionic Liquids. Chem. Commun. (2000) 20512052.

[15] F. Zhou, Y. Liang, W. Liu, Ionic Liquid Lubricants: Designed Chemistry for Engineering Applications, Chem. Soc. Rev. 38 (2009) 2590-2599.

[16] A. Cieniecka-Rosłonkiewicz, A. Sas, E. Przybysz, B. Morytz, A. Syguda, J. Pernak, Ionic Liquids for the Production of Insecticidal and Microbicidal Extracts of the Fungus Cantharellus cibarius, Chem. Biodivers. 4 (2007) 2218-2224.

[17] N. S. M. Vieira, S. Stolte, J. M. M. Araújo, L. P. N. Rebelo, A. B. Pereiro, M. Markiewicz, Acute Aquatic Toxicity and Biodegradability of Fluorinated Ionic Liquids, ACS Sustaintable Chem. Eng. 7 (2019) 3733-3741.

[18] N. S. M. Vieira, J. C. Bastos, J. M. M. Araújo, A. Matias, L. P. N. Rebelo, A. B. Pereiro. Human cytotoxicity and octanol/water partition coefficients of fluorinated ionic liquids, Chemosphere $216(2019)$ 576-586. 
[19] M. F. C. Gomes, A. A. H. Padua, Interactions of Carbon Dioxide with Liquid Fluorocarbons, J. Phys. Chem. B. 107 (2003) 14020-14024.

[20] A. Luís, K. Shimizu, J. M. M. Araújo, P. J. Carvalho, J. A. Lopes-da-Silva, J. N. C Lopes, L. P. N. Rebelo, J. A. P. Coutinho, M. G. Freire, A. B. Pereiro, Influence of Nanosegrefation on the Surface Tension of Fluorinates Ionic Liquids, Langmuir 32 (2016) 6130-6139.

[21] F. S. Teixeira, N. S. M. Vieira, O. A. Cortes, J. M. M. Araújo, I. M. Marrucho, L. P. N. Rebelo, A. B. Pereiro, Phase Equilibria and Surfactant Behavior of Fluorinated Ionic Liquids with Water, J. Chem. Thermodyn. 82 (2015) 99-107.

[22] A. B. Pereiro, J. M. M. Araújo, F. S. Teixeira, I. M. Marrucho, M. M. Piñeiro, L. P. N. Rebelo, Aggregation behavior and total miscibility of fluorinated ionic liquids in water, Langmuir 31 (2015) 1283-1295.

[23] A. B. Pereiro, F. Llovell, J. M. M. Araújo, A. S. S. Santos, L. P. N. Rebelo, M. M. Piñeiro, L. F. Vega, Thermophysical characterization of ionic liquids based on the perfluorobutanesulfonate anion: experimental and soft-SAFT modelling results, ChemPhysChem 18 (2017) 2012-2023.

[24] N. S. M. Vieira, P. M. Reis, K. Shimizu, O. A. Cortes, I. M. Marrucho, J. M. M. Araújo, J. M. S. S. Esperança, J. N. C. Lopes, A. B. Pereiro, L. P. N. Rebelo, A thermophysical and structural characterization of ionic liquids with alkyl and perfluoroalkyl side chains, RSC Adv. 5 (2015) 65337-65350.

[25] J. C. Bastos, S. F. Carvalho, T. Welton, J. N. C. Lopes, L. P. N. Rebelo, K. Shimizu, J. M. M. Araújo, A. B. Pereiro, Design of task-specific fluorinated ionic liquids: nanosegregation versus hydrogen-bonding ability in aqueous solutions, Chem. Commun. 54 (2018) 3524-3527.

[26] V. Najdanovic-Visak, J. N. C. Lopes, Z. P. Visak, J. Trindade, L. P. N. Rebelo, Salting-out in Aqueous Solutions of Ionic Liquids and $\mathrm{K}_{3} \mathrm{PO}_{4}$ : Aqueous Biphasic Systems and Salt Precipitation, Int. J. Mol. Sci. 8 (2007) 736-748. 
[27] M. G. Freire, C. M. S. S. Neves, J. N. C. Lopes, I. M. Marrucho, J. A. P. Coutinho, L. P. N. Rebelo, Impact of Self-Aggregation on the Formation of Ionic-Liquid-Based Aqueous Biphasic Systems, J. Phys. Chem. B 116 (2012) 7660-7668.

[28] G. D. Gatta, E. Badea, M. Saczuk, Thermodynamics of solvation of some linear and branched aliphatic aldehydes in water and heptane, J. Chem. Thermody. 42 (2010) 1204-1208.

[29] C. Duce, M. R. Tine, L. Lepori, E. Matteoli, Thermodynamic study of perfluorohexane + ether mixtures VLE, LLE, and HE, Fluid Phase Equilib. 269 (2008) 59-68.

[30] M. G. Freire, L. Gomes, L. M. N. B. F. Santos, I. M. Marrucho, J. A. P. Coutinho, Water Solubility in Linear Fluoroalkanes Used in Blood Substitute Formulations, J. Phys. Chem. B 110 (2006) 22923-2929.

[31] Ben-Naim, A. Molecular Theory of Solutions, Oxford, Jerusalem, 2006.

[32] E. Szajdzinska-Pietek, M. Wolszczak, Time-Resolved Fluorescence Quenching Study of Aqueous Solutions of Perfluorinated Surfactants with the Use of Protiated Luminophore and Quencher, Langmuir 16 (2000) 1675-1680.

[33] A. González-Pérez, J. M. Ruso, G. Prieto, F. Sarmiento, Apparent molar quantities of sodium octanoate in aqueous solutions, Colloid Polym. Sci. 282 (2004) 1133-1139.

[34] J. L. López-Fontán, F. Sarmiento, P. C. Schulz, The aggregation of sodium perfluorooctanoate in water, Colloid Polym. Sci. 283 (2004) 862-871.

[35] C. Florindo, L. C. Tomé, I. M. Marrucho, Thermodynamic Study of Aggregation of Cholinium Perfluoroalkanoate Ionic Liquids, J. Chem. Eng. Data 61 (2016) 3979-3988.

[36] R. Zana, Critical Micellization Concentration of Surfactants in Aqueous Solution and Free Energy of Micellization, Langmuir 12 (1996) 1208-1211.

[37] S. Das, S. Mondal, S. Ghosh, Physicochemical Studies on the Micellization of Cationic, Anionic, and Nonionic Surfactants in Water-Polar Organic Solvent Mixtures, J. Chem. Eng. Data 58 (2013) 2586-2595. 
[38] J. N. Israelachvili, D. J. Mitchell, B. W. Ninham, Theory of Self-Assembly of Hydrocarbon Amphiphiles into Micelles and Bilayers, J. Chem. Soc., Faraday Trans. 272 (1976) 1525-1568. [39] C. Tanford, Micelle Shape and Size, J. Phys. Chem. 76 (1972) 3020-3024.

[40] T. H. V. Ngo, C. Damas, R. Naejus, R. Coudert, Synthesis and Comparative Behaviour Study of Fluorocarbon and Hydrocarbon Cationic Surfactants in Aqueous Media, J. Fluor. Chem. 131 (2010) 704-708.

[41] F. Giulieri, M. P. Krafft, Can the Formation of Vesicles from Single-Chain Perfluoroalkylated Amphiphiles Be Predicted?, Colloids Surf. A 84 (1994) 121-127.

[42] V. Srinivasan, D. Blankschtein, Prediction of Conformational Characteristics and Micellar Solution Properties of Fluorocarbon Surfactants, Langmuir 21 (2005) 1647-1660. 